\title{
Una reflexión en torno a la flora, vegetación y etnobotánica en Homero
}

\section{A reflection about Homero's Flora, Vegetation and Ethnobotany}

\author{
Carolina Villagrán ${ }^{1} \&$ Tania Squizzato ${ }^{2}$ \\ ${ }^{1}$ Departamento de Biología, Facultad de Ciencias, Universidad de Chile. Las Palmeras 3425, Ñuñoa, Santiago, Chile. \\ ${ }^{2}$ Facultad Eclesiástica de Teología, Pontificia Universidad Católica de Valparaíso. Av. Brasil 2950, Valparaíso, Chile. \\ carolinavillagran.moraga@gmail.com; tania.squizzato@pucv.cl
}

\section{RESUMEN}

Este estudio constituye una contribución al conocimiento de la concepción descriptivo-mítica de la naturaleza vegetal en la época homérica, realizado sobre la base de las referencias botánicas y etnobotánicas consignadas en la Ilíada y la Odisea. El objetivo es formalizar un examen de la biodiversidad, ecología y usos de las plantas nativas y cultivadas; dimensión estética y sentido de los símiles botánicos; y claves que ofrece el poema para profundizar en el pensamiento de la geografía mítica que vertebra la visión de la naturaleza que impera en el período. El examen se realizó sobre la base de la elaboración de un Catálogo con los nombres griegos de plantas registrados en Homero, sus transliteraciones latinas, los lugares donde aparecen, los nombres españoles y científicos de los taxa, y las clases de referencias mencionadas. La evaluación de la importancia relativa y clases de relaciones de los 59 nombres griegos de plantas registrados en el Catálogo muestra que: (i) En la descripción de la flora nativa y cultivada revisten mayor importancia (19\%) las comunidades características de los ecosistemas forestales y sus especies arbóreas dominantes, como la encina, el olivo, el fresno y distintas especies de coníferas. En el paisaje cultural, los cereales y la vid; (ii) Entre las clases de referencias botánicas homéricas, el uso del recurso poético del símil -que destaca las comparaciones con elementos vegetales- corresponde al segundo lugar en importancia (17\%); (iii) Los elementos míticos corresponden a un 13\% del total de las relaciones consideradas, sea en la atribución de poderes mágico-terapéuticos y características sobrenaturales adjudicadas a ciertas plantas o comunidades vegetales; sea en la función de plantas sagradas en rituales y ceremonias; (iv) Las restantes clases de relaciones botánicas se refieren a usos de la flora, sea en construcción, artesanías, alimentación, forraje, u otras prácticas varias. Se destacan dos conclusiones principales: (i) rol fundante del poema homérico en Historia Natural, tanto en la inauguración de la nomenclatura como en terminología botánica; (ii) trascendencia del símil poético y del mito homérico que incluyen plantas -como simbolismo del sentido de la condición humana-.

Palabras clave: Homero, nomenclatura, comparaciones poético-botánicas, plantas míticas

\begin{abstract}
This study contributes to the knowledge of the mythical-descriptive conception of the vegetable kingdom in Homeric times, based on the botanic and ethnobotanic references made in the texts of the Iliad and the Odyssey. The aim of the work is to examine the biodiversity, ecology, and uses of indigenous and cultivated plants; the aesthetic dimension and the sense of the botanical simile; and the keys that the poem offers to dwell into the mythical geography underlying the vision of nature that permeates the period. The examination was done on the basis of the elaboration of a Catalog with the Greek names of plants registered in Homer, their Latin transliterations, the places where they appear, the Spanish and scientific names of the taxa and the mentioned classes of relationhips. The evaluation of the relative importance and relationships of the 59 Greek plant names cited in the Catalog demonstrate that: (i) In the description of indigenous and cultivated plants, native forest communities and their component tree species attain greater importance (19\%), including oaks, olive trees, ashes and several conifer species. In the cultural landscape, cereals and grapevines predominate. (ii) Among the botanical references made by Homer, the poetic form of simile -emphasizing comparisons with vegetable elements- is second in importance (17\%). (iii) The mythical elements represent 13\% of the references, which are given magic-therapeutic powers or assigned supernatural characters focused on certain plants and plant communities, as sacred plants in ritual ceremonies. (iv) The remaining botanical classes make reference to practical uses of the flora, as objects for construction, arts and crafts, sources of foods, forage and so on. We highlight two main conclusions: (i) the founding role of the Homeric poems in regard to Natural History, by introducing both nomenclatural and terminological botany, (ii) the transcendence of the poetic comparison and Homeric myth that considers plants as symbols of the sense and human condition.
\end{abstract}

KEYWORDS: Homero, nomenclature, botanical-poetic comparisons, mythical plants. 


\section{INTRODUCCIÓN}

"Si es verdad, como lo es sin duda, que Homero fue modelo de Virgilio quien a su vez lo fue de Dante y Milton; que la literatura latina se inaugura con la traducción que hizo Livio Andrónico de la Odisea; que en Ennio alentaba, al menos metafóricamente, el alma de Homero; y que este eximio poeta griego inspiró ya en tiempos modernos a Tennyson, Kazantzakis y James Joyce, podemos afirmar sin hipérbole que la literatura occidental de alguna manera comienza con Homero y ya no le abandona nunca. [...] el poeta divino (que así lo calificaron Demócrito, Aristófanes y Platón) influyó decisivamente en el arte, la literatura, la lengua, la religión y la filosofía griega" (López Eire 1997)

La literatura occidental se inaugura con dos poemas monumentales: la Ilíada (de más de 15.000 versos) y la Odisea (de más de 12.000). Atribuidas al poeta Homero, ambas obras han tenido una importancia decisiva no solo en la literatura y cultura de los griegos, sino también -como sugiere el epígrafe- en la nuestra. Dotados de profunda sabiduría y de una belleza ejemplar, durante siglos estos poemas determinaron la poesía posterior (la lírica arcaica, la tragedia, la lírica alejandrina, etc.) -hecho por lo demás patente-, pero además se constituyeron en fuente de las más diversas disciplinas ${ }^{1}$. Homero, como se ha dicho ya muchas veces, fue el educador de Grecia. Y, si los griegos aprendieron de Homero y los occidentales aprendieron de los griegos, resulta comprensible que la Ilíada y la Odisea se nos presenten como el punto de partida para el estudio de las artes y ciencias de Occidente. Ya otros han mostrado la importancia que estos dos poemas tienen en la investigación sobre el lenguaje, la literatura, el arte, la historia y la filosofía; podemos añadir nosotros ahora la botánica. Pues, en la Ilíada y en la Odisea se encuentra, por primera vez, el nombre de cerca de 60 taxa, que constituyeron una de las fuentes de la Historia de las plantas de Teofrasto ${ }^{2}$, el padre de la botánica.

Sobre la base de tal diversidad de taxa, la indagación que se ofrece en el presente estudio abarca el espacio de la vegetación mediterránea que se despliega en la épica homérica. Además de evaluar el caudal de matices de los símiles botánicos del poema, es de nuestro interés abrirnos hacia una reflexión en torno a los saberes botánicos y

\footnotetext{
${ }^{1}$ En el diálogo platónico Ion (Lledó 1985) se nos muestra que los griegos acudían a la obra de Homero para instruirse en adivinación, medicina, estrategia militar, conducción de carros, navegación, pesca, entre otros muchos saberes.

${ }^{2}$ Díaz-Regañón 2008, p. 13.
}

etnobotánicos de la época. Con este propósito se formaliza un examen de la riqueza de nombres de la flora, biodiversidad, formas, ecología, distribución y usos de las plantas nativas y cultivadas registradas. Más allá de esta exploración centrada en el conocimiento y técnicas culturales asociadas a las plantas, nos interesa también reflexionar en torno a las valiosas claves que ofrece el poema para profundizar en el pensamiento mítico que vertebra la visión de la naturaleza que reina en el período ${ }^{3}$.

\section{MATERIALES Y MÉTODOS}

El trabajo se articula en cuatro partes. Primero se realiza una descripción general de la geografía botánica en la obra de Homero; luego se analizan y comentan las referencias botánicas en la dimensión estética (figura poética del símil o comparación) y en el ámbito artesanal, alimenticio y de usos varios; finalmente, en la dimensión mítica, míticomedicinal y ceremonial.

Como anexo se presenta un Catálogo, que pretende ser exhaustivo, con los 59 nombres griegos de plantas registradas en la Ilíada y en la Odisea ${ }^{4}$, sus transliteraciones latinas y los lugares donde aparecen. El Catálogo también consigna los nombres científicos de las especies, los géneros y las familias de las plantas mencionadas. La determinación botánica de los taxa sigue principalmente el criterio de Liddell et al. 1989, Teofrasto (Historia Plantarum ${ }^{5}$ ), y otras fuentes que se documentan en el texto. Los nombres españoles corresponden a las traducciones de Crespo 1996 de la Ilíada y a la de Pabón 1982 de la Odisea ${ }^{6}$ En el Catálogo también se sintetizan las clases de referencias reseñadas para cada taxon: descriptiva, símil, mítica, construcción y artesanía, alimentación, forraje, referencias espaciales y relaciones varias. Adicionalmente, se incluyen gráficos donde se destaca la relevancia de los taxa mencionadas con mayor frecuencia en la obra (Fig. 1) y las contribuciones relativas a cada clase de referencias de la flora (Fig. 2).

\footnotetext{
${ }^{3}$ Durante la Revisión Editorial, uno de los árbitros nos señaló la existencia de un artículo de Forster (1936). Este autor aborda el tema de nuestro texto y considera gran parte de las plantas citadas por Homero, focalizándose principalmente en la botánica práctica de la cotidianidad. Consideramos que nuestra contribución complementa muy bien esta investigación pionera iniciada por Forster, en la medida en que damos énfasis al rol fundante de la nomenclatura botánica homérica en el desarrollo de la Historia Natural, y al rol de las plantas en los símiles botánicos y cosmovisión mítica de la naturaleza.

${ }^{4}$ Texto griego de Monro \& Allen 1920.

${ }^{5}$ En adelante HP. Texto griego de Hort 1916, traducción española de Díaz-Regañón (2008).

${ }^{6}$ Todas las traducciones de los versos homéricos corresponden a Crespo (Ilíada) y Pabón (Odisea), salvo que se indique otra cosa.
} 


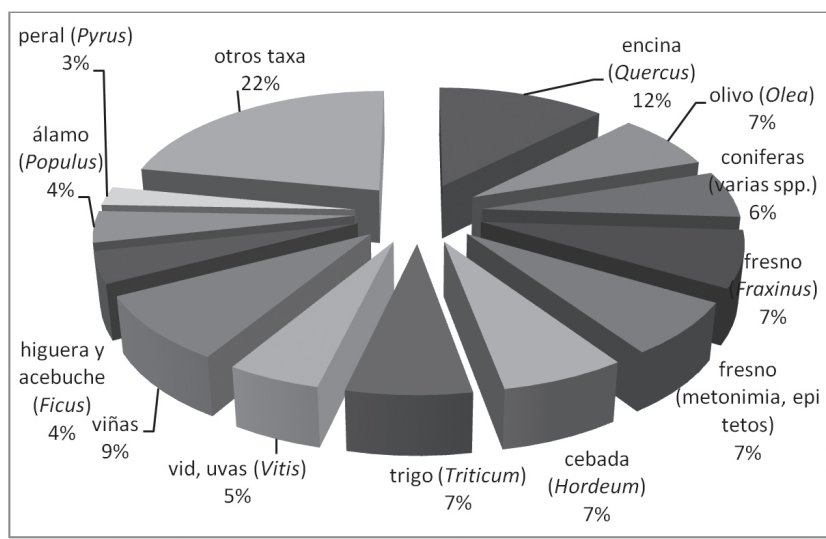

Figura 1. Referencias taxonómicas en Homero ( $\mathrm{N}=242)$. / Taxonomic References in Homer $(\mathrm{N}=242)$.

\section{RESULTADOS}

\section{GeOgRafía BOtÁNICA EN Homero}

Los árboles característicos de los ecosistemas de bosques mediterráneos revisten especial importancia en la representación de la geografía botánica homérica. Dos taxa forestales destacan, por su recurrente mención en distintos contextos del poema, ya sea en las descripciones de los bosques nativos o bien en múltiples clases de relaciones -sean poéticas, míticas, ceremoniales, espaciales o usos variados en construcción y artesanías (Figs.1 y 2)-. Las encinas, especies de Quercus de la familia Fagáceas, consagradas a Zeus y dominantes en el paisaje vegetal de la antigua Grecia, ocupan el primer lugar en importancia y abarcan un $12 \%$ del total de menciones de plantas en Homero (Fig. 1). Son citadas principalmente en la Ilíada, en múltiples y variadas clases de referencias (ver Catálogo). Dos vernáculos que consignan especies de encinas aparecen en los poemas: phēgós, nombre que ha sido adjudicado a Quercus macrolepis T. Kotschy, registrado solamente en la Ilíada, y drys, nombre con un rango más amplio de inclusión botánica y que, de acuerdo con la información etnohistórica (Teofrasto $H P$ ) y con la distribución geográfica actual del género Quercus, podría incluir a $Q$. robur L., $Q$. ilex L., $Q$. cerris L. y $Q$. pubescens Willd., todas hoy muy abundantes en torno a la cuenca mediterránea ${ }^{7}$.

Entre las especies forestales homéricas más significativas, corresponde también un rango importante al olivo, gr. elaía

\footnotetext{
${ }^{7}$ Otras tres palabras destacan la importancia de las encinas en la obra. Dos nombres se refieren al fruto de las encinas, las bellotas, un importante aporte alimenticio y forrajero: bálanos, que consigna los frutos de las especies de Quercus, en general; y akylos, probablemente los frutos de $Q$. ilex L. (vide supra, 4); el término drymá nombra las comunidades dominadas por especies de encinas, los encinares.
}

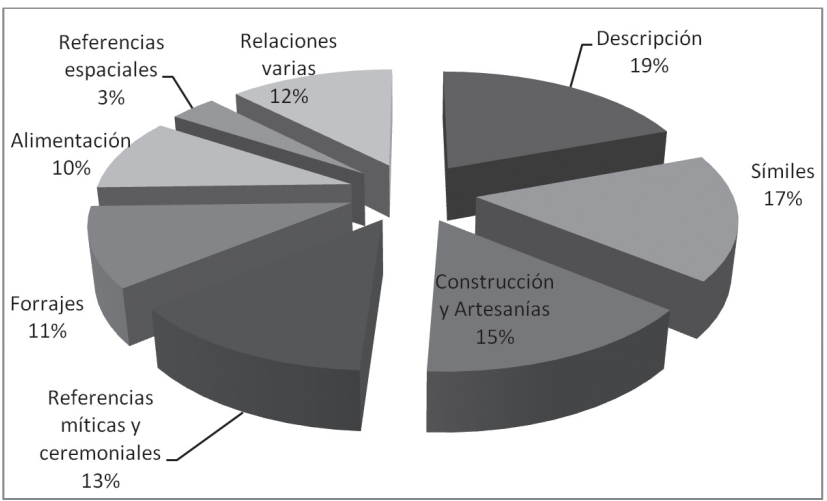

FIgURA 2. Clases de relaciones botánicas consignadas en Homero $(\mathrm{N}=114)$. / Classes of botanical relationships recorded in Homer $(\mathrm{N}=114)$.

(Olea europea L., Oleáceas), el árbol consagrado a Atenea ${ }^{8}$ y que ocupa un lugar central en la horticultura griega. Integra un 7\% (Fig. 1) del total de citaciones, principalmente en la Odisea, en contextos referenciales múltiples, con predominio de la función ceremonial-ritual (ver Catálogo). La fina observación naturalista de Homero se refleja en la distinción de subespecies y variedades de Olea europaea, con vernáculos propios: el olivo cultivado, gr. elaía $(O$. europaea L. subsp. cuspidata); y el acebuche, gr. phylía ( $O$. europaea L. subsp. europaea var. silvestris): "Entro él en la mitad de las frondas / de dos tallos brotados del mismo lugar, que era el uno / el acebuche y el otro el olivo" ( $O d$. V 476-478).

Un caso especial lo constituye el fresno, gr. melié (Fraxinus ornus L., Oleácea), que figura con un 7\% del total de citaciones (Fig. 1). Sin embargo, el sustantivo meliée consigna al "fresno" como taxon solamente en dos ocasiones en la Ilíada, en contexto descriptivo o de símil poético (XIII 178, XVI 767), y en otras dos ocasiones en la Odisea (XIV 281, XVII 339), como material de construcción o para la fabricación de lanzas. El adjetivo meílinos, "de fresno", derivado del sustantivo meliée, que aparece muchísimas veces en la Ilíada, siempre como epíteto del sustantivo "lanza".

\footnotetext{
${ }^{8}$ Según una leyenda posterior a Homero, Atenea y Poseidón se disputaron el dominio de la ciudad de Atenas. Poseidón hizo brotar en medio de la Acrópolis una fuente de agua salada y Atenea plantó un olivo en la cumbre de la colina. Los árbitros dispuestos por Zeus se decidieron en favor de Atenea (cfr. Grimal 1951, p. 92).

${ }^{9}$ Por otra parte, una proporción de $7 \%$ de las citaciones integra conceptos relacionados con la palabra "fresno" en otros dos sentidos: (i) En la Ilíada, el sustantivo meliee designa por metonimia en diez ocasiones el nombre de la lanza de Aquiles en particular y una sola vez "lanza" en general; (ii) el adjetivo compuesto eümelies, "armado con lanza de buen fresno", aparece seis veces en la Ilíada y una sola vez en la Odisea y funciona siempre como epíteto. Curiosamente, en la Ilíada
} 
Distintas especies de Coníferas ocupan también un lugar relevante en la obra, principalmente como material de construcción de casas y embarcaciones. En conjunto, los taxa de Coníferas corresponden a un $6 \%$ del total de citaciones (Fig. 1). Entre las especies de la familia Pináceas, figuran el abeto, gr. elátē (Abies cephalonica Loud.), el cedro, gr. kédros (especies de Cedrus) y el pino, este último consignado con dos vernáculos: pitys, adjudicado a Pinus nigra Arn. subsp. salzmannii (Dunal) Franco, y peúkē, de mayor inclusión botánica, abarcando varias especies de Pinus y, probablemente, de Picea. Tal como se reseñara para el fresno, en el caso del abeto el sustantivo elátē consigna el árbol como tal y también, por metonimia ${ }^{10}$, el "remo" hecho de abeto (Il. V, 7; Od. XII 172). Entre las Coníferas de la familia Cupresáceas, se menciona el ciprés, kypárissos (Cupressus sempervirens L.) y el alerce africano o tuya, thýon (Tetraclinis articulata (Vahl) Masters).

A diferencia de la Ilíada, la Odisea despliega con magnificencia una serie de escenarios botánicos cuya descripción denota el refinamiento estético de la mirada homérica. Gran parte de las reseñas acerca de la vegetación silvestre provienen de un espacio mítico, una serie de islas de ubicación desconocida y habitadas por seres no humanos, que viven rodeados de bosques y en armonía con la naturaleza. Así la arboleda en la isla de los Cíclopes, "con altísimos pinos y encinas de excelso ramaje" (Od. IX 186); "emboscada en laureles" (Od. IX 183) -en este lugar y por única vez se menciona el laurel, dáphnē (Laurus nobilis L., Lauráceas), otro de los árboles de gran significado simbólico en la mitología griega, consagrado a Apolo ${ }^{11}$ - Así el palacio de la diosa Circe, "en espeso encinar" [drymá] (Od. X 150); así la bella descripción de la arboleda y de los prados en torno a la gruta de la ninfa Calipso:

A la cueva servía de cercado un frondoso boscaje / de fragantes cipreses, alisos y chopos, en donde / tenían puesto su nido

es siempre epíteto de troyanos: tres veces referido al anciano Príamo (IV 47, 165, VI 449); y tres veces referido a hijos del anciano Pántoo: de Euforbo (XVII 9, 59) y de los hijos de Pántoo en general (XVII 23). Son los troyanos los que tienen lanzas de buen fresno. En la Odisea es epíteto de Pisístrato, hijo de Néstor (III 400).

${ }^{10}$ Autores posteriores a Homero utilizaron la palabra $\dot{\varepsilon} \lambda \alpha \dot{\tau} \tau \eta$ para designar, por metonimia también, al "barco" (así el poeta lírico arcaico Alceo, fr. 444, Lobel \& Page 1955). No es de extrañar que, en la antigüedad, las naves fueran construidas con abeto, puesto que posee una madera propicia para flotar, como señala Homero en Odisea IV 240. También es interesante notar que en latín ocurre algo semejante con la palabra abies, "abeto", que designa al árbol y por metonimia, también al barco (entre otras acepciones).

${ }^{11}$ En la Metamorfosis I, vv. 452-566, de Ovidio (Álvarez \& Iglesias 1999) se presenta el mito de la ninfa Dafne quien, huyendo de Apolo, invoca a su padre por una metamorfosis: su piel se convierte en corteza de árbol, su cabello en hojas, sus brazos en ramas y sus pies se enraízan en la tierra. Apolo le promete que la amará eternamente como su árbol, el laurel, y que sus ramas coronaran las cabezas de los héroes. unas aves de rápidas alas, / alcotanes y búhos, chillonas cornejas marinas... / En el mismo recinto y en torno a la cóncava gruta / extendíase una viña lozana, florida de gajos. / Cuatro fuentes en fila, cercanas las cuatro en sus brotes, / despedían a lados distintos la luz de sus chorros; / delicado jardín de violetas y apios brotaba / en su torno: hasta un dios que se hubiera acercado a aquel sitio / quedaríase suspenso a su vista gozando en su pecho (Od. V 63-74).

En la descripción del paisaje forestal, y sus tipos de comunidades, adquieren relevancia ciertas especies de árboles higrófilos, adaptados a hábitats húmedos y pantanosos, componentes característicos de los bosques mediterráneos en galería, asociados a las orillas de los ríos, lagos, canales y pantanos. Entre los árboles de humedales destacan algunos de la familia Salicáceas: los sauces, gr. itéa (Salix alba L. y S. amplexicaulis Borg); el álamo negro o chopo, gr. aigeiros (Populus nigra L.); y blanco, gr. acherōis (P. alba L.); asociados al olmo, gr. pteléa (Ulmus glabra Huds., Ulmácea) y al aliso, gr. klēthra (Alnus glutinosa (L.) Gaertn., Betulácea). También es higrófila la vegetación ribereña arbustiva y herbácea, como las praderas húmedas dominadas por lotos, gr. lōtós, especies forrajeras de la familia Fabáceas; junquillares y vegas, con especies palustres características, principalmente Ciperáceas como la juncia, gr. kýpeiron; y distintos tipos de juncos, por ejemplo, los pertenecientes a las familias Juncáceas, thrýon, y Poáceas herbáceas, schoînos. Asimismo, la vegetación de cañaverales, estructurados por grandes Poáceas subleñosas (Sub-familia Arundinonídeas), como la caña, gr. donax (Arundo donax L.) y el cañizo o carrizo, gr. órophos (probablemente, Phragmites australis (Cav.) Trin.).

En la Ilíada se presentan algunos ejemplos de la composición de la vegetación de humedales alrededor del cauce del río Escamandro (Janto), con sus componentes arbóreos higrófilos, junquillares y praderas húmedas: "Ardían los olmos, los sauces y los tamariscos; ardía el loto, el junco y la juncia" (Il. XXI 350-351). También en la Odisea algunas descripciones de la vegetación están signadas por la presencia de plantas asociadas a la humedad. Así el Hades: "Una extensa llanura hallarás con los bosques sagrados de Perséfona, chopos ingentes y sauces que dejan frutos muertos" $\left(O d\right.$. X 509-510) ${ }^{12}$. Desde estos bosques sagrados se accede a los prados de asphódelos (Asphodelus ramosus L., Xanthorrheacea), la morada de los muertos: "Del océano a las ondas llegaron, al cabo de Leucas, a las puertas del sol, al país de los sueños, y pronto descendiendo

\footnotetext{
${ }^{12} \mathrm{Al}$ respecto, Teofrasto afirma que "el sauce deja caer su fruto pronto, antes de que madure completamente y esté en sazón; por lo cual no anda descaminado el poeta [i.e. Homero] al apellidarlo «perdedor de su fruto»" (HP III, 1, 3).
} 
vinieron al prado de asfódelos, donde se guarecen las almas, imágenes de hombres exhaustos" (Od. XXIV 11-14).

LA PRESENCIA VEGETAL EN LA FIGURA POÉTICA DEL SÍMIL El símil o comparación es un recurso poético que consiste en establecer una relación, mediante una partícula comparativa, entre dos elementos diversos que poseen una cualidad en común. Esta figura poética es utilizada profusamente por Homero tanto en la Ilíada como en la Odisea, aunque es mucho más frecuente en la primera, donde el símil se halla ampliamente diseminado por toda la obra. En ambos poemas no solo abundan las comparaciones en general, sino también aquellas donde aparecen elementos del mundo vegetal, de allí que, después de las descripciones, los símiles poéticos ocupen el segundo lugar en importancia entre las referencias botánicas en la obra de Homero (17\%, Fig. 2).

En la Ilíada se observa una veintena de símiles donde se manifiesta el mundo vegetal. En muchas ocasiones los seres humanos son comparados con árboles y plantas, sea que se los tome individualmente, sea que se los considere en su conjunto.

Dos de las características físicas predominantes de los héroes homéricos son la elevada estatura y la fuerza o robustez. De allí que, en general, los guerreros sean comparados con árboles altos y/o robustos, sobre todo al momento de señalar su caída. Así, por ejemplo, se desploman los jóvenes gemelos Cretón y Orsíloco, que habían llegado a Troya para honrar a los Atridas: “ambos, bajo los brazos de Eneas doblegados, cayeron abatidos, semejantes a elevados abetos" (Il. V 559-560).

La muerte de Sarpedón, importantísima para el desarrollo argumental de la obra, es ampliamente desarrollada por Homero en el canto XVI. Sarpedón, caudillo de los licios e hijo - nada menos que- de Zeus, había ido al encuentro de Patroclo, que estaba haciendo estragos entre los troyanos, para saber quién era el que portaba las armas de Aquiles, ávido de enfrentar a un guerrero poderoso. Ya en el duelo singular, dos veces falla Sarpedón y en cambio le acierta Patroclo en su pecho. Entonces el hijo de Zeus, en cuyo honor el rey de los dioses hizo llover gotas de sangre sobre el campo de combate,

"se desplomó, como cuando se desploma una encina, un álamo blanco o un pino talludo que en los montes los carpinteros talan con recién afiladas hachas para convertirlos en quilla; así quedó aquél tendido ante los caballos y la caja del carro bramando y cogiendo con crispación el ensangrentado polvo" (Il. XVI 482-486).

A diferencia del símil anterior, la caída de un héroe tan importante como Sarpedón es encarecida con la mención de tres árboles sucesivos: la encina, robusta; el álamo, alto; y el pino, alto y robusto ${ }^{13}$. La magnitud corporal de un guerrero también se aprecia cuando yace tendido en el suelo (así, por ejemplo, lo primero que admiran sus adversarios al ver el cuerpo caído de Héctor es su estatura y envidiable belleza, cf. XXII 370). Otros dos héroes, al caer, son comparados con un álamo negro y un fresno, respectivamente. La riqueza de la comparación en el primer caso radica, además, en que el poeta desarrolla el símil incorporando en la escena de la muerte heroica elementos de la vida cotidiana. Así, entonces, en el canto IV, un joven troyano muere doblegado por Ayante Telamonio:

"Cayó a tierra en el polvo, como el álamo negro que en la vega de una extensa marisma ha crecido con el tronco liso, aunque unas ramas nacen en su cúspide, y que el carretero tala con el fogueado hierro para curvarlo como llanta para un carro, de bello contorno; y el álamo yace secándose a lo largo de la orilla del río" (Il. IV 482-487).

Más adelante, Teucro Telamonio quitó la vida a Imbrio que "destacaba entre los troyanos", pero "cayó como el fresno que en la cima de un monte cuya silueta es visible desde lejos talado por el bronce desploma al suelo su tierno follaje" (Il. XIII 178-180). Aquí el punto de comparación es la belleza y frescura del fresno que antes destacaba en la cima de un monte, como descollaba el muchacho entre los troyanos, y ahora la juventud del guerrero yace en el polvo, como por tierra se extiende el tierno follaje del fresno.

No solo los guerreros tomados individualmente son comparados con árboles, sino también cuando son considerados como hueste en su conjunto. A fin de destacar la fuerza necesaria para combatir en la llanura de Troya, los héroes son comparados una y otra vez con árboles poderosos sometidos a la furia de los vientos o la violencia de los ríos torrentosos. Así, pues, para exaltar la fuerza de Ayante, el mejor de los aqueos mientras duró la cólera de Aquiles (II 769), Homero compara a sus enemigos con la vegetación que no puede resistir el caudal de un río desbordado:

"Como cuando un río desbordado desciende a la llanura montes abajo, torrencial y acrecido por el aguacero de Zeus, e incorpora numerosas encinas resecas y numerosos pinos a su caudal $\mathrm{y}$ vierte gran cantidad de fango en el mar, así el preclaro Ayante atropellaba y acosaba la llanura entonces, exterminando hombres y caballos" (Il. XI 492-497).

Nuevamente en el canto XVI, donde se narra la contra ofensiva aquea encabezada por Patroclo, los troyanos, favorecidos por Zeus, luchaban ya en el campamento

\footnotetext{
${ }^{13} \mathrm{El}$ mismo símil aparece referido a otro héroe de menor rango en el $\mathrm{Il}$. XIII, 389-393.
} 
aqueo y estaban a punto de prender fuego a las naves. Los aqueos habían recobrado bríos con la incorporación del compañero de Aquiles y el ejército de los mirmidones en la batalla. Ambos bandos, embravecidos por igual, llevaron juntamente una feroz contienda y se destruían mutuamente como las ramas de los árboles que son objeto de la furia de los vientos encontrados:

"Como el Euro y el Noto rivalizan entre sí en las cárcavas de un monte por agitar un espeso bosque de encinas, de fresnos y de cornejos, de tersa corteza, que entrechocan mutuamente con portentoso estruendo sus extendidas ramas, que crepitan al troncharse, así los troyanos y los aqueos se acometían impetuosos y se aniquilaban sin recordar unos ni otros la funesta huida" (Il. XVI 765-771).

En la Ilíada una y otra vez se nos recuerda que la muerte aguarda a todos, valientes o cobardes, y que el combate doblega por igual a los hombres. Esta última idea es expresada en una imagen bellísima: los héroes, al caer en uno y otro bando, son comparados con espigas de trigo, que caen a uno y otro lado de la siega.

"Como los segadores en dos filas, unos frente a otros, por el labrantío de un hombre dichoso recorren el surco de trigo o de cebada, y las brazadas van cayendo densas, así los troyanos y los aqueos se acometían unos a otros y se aniquilaban sin acordarse de la funesta huida" (Il. XI 67-71).

En este símil el contraste es mucho más fuerte en la medida en que Homero introduce la actividad de los hombres en los tiempos de paz y contrasta la dicha de aquel que posee un campo de trigo y jornaleros que lo trabajen, con la desdicha de los hombres que se destruyen entre sí en una guerra.

La única vez que se menciona el olivo en la Ilíada es para introducir uno de los símiles más hermosos y conmovedores de la obra. Aquí la vida entera del joven príncipe Euforbo es comparada con la de un olivo:

"De sangre se empapó su cabello, semejante al de las Gracias, y los bucles, que formaban avisperos sujetos con oro y plata. Cual floreciente pimpollo de olivo que un hombre planta en un paraje solitario que el agua riega en abundancia, y éste crece bello y frondoso; lo mecen las brisas de los diversos vientos y se cubre de blanca flor, pero de repente llega el huracán con gran vendaval, lo arranca del hoyo y lo extiende por el suelo, así al hijo de Pantoo, Euforbo, el de buena lanza de fresno, el Atrida Menelao lo mató y lo despojó de la armadura" (Il. XVII 51-60).
Es posible advertir en este símil el cuidado amoroso del padre que, después de haberlo engendrado, procura que su hijo crezca en las mejores condiciones (en la soledad de una comarca, donde se desarrolla el olivo sin que otros árboles le quiten la luz, sin que le falte el agua nutricia y donde es mecido por apacibles vientos). Sin embargo, una vez que el hijo alcanza la flor de la juventud, la guerra le arrebata la vida como el huracán arranca el olivo. También Tetis ha criado a su hijo Aquiles con el mismo esmero con que los hombres cuidan un viñedo: "él creció semejante a un retoño, yo lo crie como a una planta de vid en la colina" (Il. XVIII $57=437)$ y también al joven Aquiles le acecha la muerte.

Hay un par de símiles donde no se compara la vida o el cuerpo de los héroes en su conjunto, sino que se toma un gesto como punto de comparación. La cabeza que pende tras ser cortado el cuello, con gran delicadeza es comparada con la flor de la amapola, gr. mēkōn (Papaver somniferum L.), que inclina su tallo combándose al peso del fruto: “como la adormidera en el jardín inclina el copete a un lado bajo el peso del fruto y de los aguaceros primaverales, así se combo a un lado su cabeza bajo el peso de la celada" (Il. VIII 306308). En otro pasaje, el ímpetu de Héctor se precipita a tierra como se derriba una encina por el rayo de Zeus:

"Como cuando a causa del impacto del padre Zeus cae una encina abatida de raíz, y el temible olor del azufre se esparce desde ella, y desfallece en su valor el que lo contempla y está cerca, pues duro es el rayo del excelso Zeus, tan de repente cayó al suelo la furia de Héctor en el polvo" (Il. XIV 414-418).

Hay un solo símil donde se habla de la resistencia, no ya de la caída, de dos héroes que se comparan con encinas. Los dos guerreros, apostados en las puertas del campamento aqueo, soportan la embestida de los enemigos con la misma firmeza con que las encinas soportan el embate del viento y la lluvia en los montes:

"Los dos estaban ante las elevadas puertas de pie, como en las montañas las encinas de elevada copa, que aguantan todos los días el viento y la lluvia, asentadas en profundas y dilatadas raíces; así ambos, confiados en sus brazos y en su fuerza, aguantaban el ataque del alto Asio sin darse a la huida" (Il. XII 131-136).

Los árboles y las plantas se introducen en varios símiles más, aunque ya no para establecer puntos de comparación con los seres humanos. Así, por ejemplo, el vocerío del combate es más fuerte que el bramido del viento entre las encinas (XIV 398), o los troyanos no tienen ningún socorro, como las crías de una cierva que ha huido a esconderse en un encinar (XI 118), o se protegen como ciervos en un bosque (XV 273). Hay también un símil donde se comparan 
las flechas con el salto de las habas y garbanzos cuando escapan de sus vainas (XIII 589).

El interés de Homero por el mundo vegetal es tan patente que, al comienzo de la obra, en el momento en que Aquiles para hacer un gran juramento levanta el cetro, se pone a describirlo: "Por este cetro, que ya nunca ni hojas ni ramas hará brotar, una vez que ha dejado en los montes el tocón, no volverá a florecer, pues el bronce le peló en su contorno las hojas y la corteza,..." (Il. I 234-237).

Finalmente, no es posible terminar esta referencia a los símiles en los que comparece la naturaleza vegetal en la Ilíada, sin mencionar el más famoso y significativo, aquel que sintetiza, de la manera más clara y hermosa, el tema de fondo de toda la obra: la fugacidad y la fragilidad de la existencia humana,

"Como la generación de las hojas, tal es también la de los hombres. Las hojas, unas echa el viento a tierra, otras las hace crecer el bosque al florecer, cuando llega la estación de la primavera; así la generación de los hombres, una brota y otra llega a su fin" (Il. VI 146-149. Trad. propia).

La inseguridad radical del hombre, el gran tema de la obra de Homero ${ }^{14}$, habrá de tener importantes repercusiones en toda la poesía griega posterior.

Aunque el símil en la Odisea es -como se dijo-menos frecuente, no por ello es menos eficaz. En este poema en solo cinco ocasiones se establecen comparaciones entre ciertas formas, órganos, estructuras o dinámicas vegetales con la belleza del cuerpo humano o de ciertas actividades del hombre vinculadas poéticamente con su devenir y destino.

En el primer símil que encontramos, se compara la levedad y fragilidad de la pequeña balsa de Odiseo con el vilano (gr. ákantha $)^{15}$. Después de ocho años en la isla de

\footnotetext{
${ }^{14}$ Cfr. Il. XVII 446ss: "Pues nada hay sin duda más mísero que el hombre de cuanto camina y respira por toda la tierra" (véase también Od. XVIII 129ss); Il. XXI 464ss: "míseros mortales, que, semejantes a las hojas, unas veces se hallan florecientes, cuando comen el fruto de la tierra, y otras veces se consumen exánimes".

${ }^{15}$ Posiblemente, el sentido de la palabra homérica ákantha es el de "vilano", la unidad de dispersión característica de la gran familia Asteráceas: una coronita de pelos, cerdas o escamas que rodea a los diminutos frutos de las Asteráceas (aquenios) para su diseminación por el viento (anemocoría). Liddell et al. 1989 refieren ákantha a cualquier planta espinosa, probablemente Eryngium campestre L., Asterácea. Sin embargo, no hay ningún indicio en el verso de Homero para adjudicar la palabra ákantha a una especie, género o cualquier otra categoría taxonómica dentro de la familia Asteráceas, en particular. Considerando el conservadurismo de la unidad de dispersión de las Asteráceas, su comportamiento con el viento, la enorme diversidad (ca. 23,500 especies) y la extensa distribución global de la familia, pareciera que la mejor interpretación botánica de la palabra ákantha del verso homérico sea "vilano", la unidad de dispersión característica de los taxa pertenecientes a la familia Asteráceas, en general. Concordantemente, ákantha en griego significa "espina" (ảkń,
}

la ninfa Calipso, el héroe se hace a la mar, por voluntad de los dioses, en una pequeña balsa, que con sus propias manos construyó. Al divisarlo, Poseidón, lleno de rencor, provoca una tempestad. La pequeña balsa, juguete de los "huracanados vientos" en la inmensidad del mar, es comparada con los vilanos que se arremolinan en el campo, en el último verano. La comparación gusta tanto a Homero, que destina seis versos para desarrollarla, y en ella ingresan los cuatro vientos de la poesía antigua.

"Como cuando al final del verano Bóreas lleva los vilanos / de un lado a otro de la llanura, y se mantienen apretados unos contra otros, / así por el mar la llevaron los vientos de aquí para allá, / unas veces el Noto empuja al Bóreas para que lo arrastre, / otras veces el Euro parece perseguir al Céfiro" (Od. V 328-332. Trad. propia).

Entre las maravillas que observa asombrado Odiseo al llegar al espléndido palacio de Alcínoo, están las cincuenta sirvientas dedicadas a distintas labores: "molían / en soleras las unas los trigos dorados, las otras / atendían al telar o sentadas hacían que la rueca / diese vueltas igual que las hojas del álamo esbelto" (Od. VII 104-106). El movimiento de las ruecas recuerda al poeta la oscilación del follaje de los álamos negros, cuando agita el viento sus frágiles pecíolos.

Uno de los momentos más emotivos de la obra es el encuentro de Penélope con Odiseo, quien, bajo el aspecto de mendigo, le cuenta una falsa historia de sí mismo y dice haber hospedado a Odiseo, en Creta, antes de que partiera a Troya. La reina llora por su esposo, sin saber que está a su lado, y el rey sufre por ella sin poder consolarla. Penélope necesita pruebas, por lo que pregunta al mendigo cómo iba vestido Odiseo, prueba que el falso mendigo sortea sin ninguna dificultad, hasta el punto de que se detiene a describir una a una las piezas de su vestimenta. Cierra y corona la descripción el detalle de la túnica, que en su ruedo semeja la piel de una cebolla, de suave textura y resplandor: "Y una túnica espléndida vi que a tu esposo cubría / con aspecto de piel de cebolla ya enjuta: tal era / de pulida y suave y al sol semejante en su brillo" (Od. XIX 232-234).

De los dos símiles restantes, en uno se compara una parte del cuerpo humano con una parte de una planta, en otro, una esbelta palmera con el cuerpo de una mujer. En las dos oportunidades en que Atenea interviene para embellecer a Odiseo, ante Nausícaa primero (VI), ante Penélope después (XXIII), la gracia de los cabellos de Odiseo es comparada con la bella flor del jacinto, gr. hyákinthos (Hyacinthus spp., Asparagáceas): "los densos cabellos / le brillaron pendientes de nuevo cual flor de jacinto" (Od. VI 230-231=XXIII 157-

akế, "espina”, ơv $\theta 0 \varsigma$, ánthos, "flor”), la coronita de puntas (cáliz transformado) que rodea la corola y persiste en torno del fruto de las Asteráceas. 
158). Con esto el poeta nos informa que el cabello de Odiseo poseía tupidos bucles y que además estaban perfumados, de lo contrario no podrían ser semejantes al jacinto, que posee una densa espiga de fragantes flores, con pétalos curvados hacia afuera como el cabello ensortijado.

Tal vez la más bella de las comparaciones en la obra sea la que forma parte del cuádruple elogio con que Odiseo intenta ganarse la voluntad de Nausícaa en el canto VI. Náufrago y de aspecto temible, se encuentra con la princesa que, por ardid de Atenea, había ido a las costas a lavar la ropa. El héroe, afamado por su astucia, comienza por comparar a la hija de Alcínoo con una diosa; luego expresa el gozo que la contemplación de tal muchacha provoca en su familia, primero, y en un esposo, después. Finalmente, y como remate de la lisonja, Odiseo sostiene que el asombro que siente al verla solo es comparable con aquel que sintió una vez frente a un retoño de palmera, gr. phoînix (Phoenix dactylifera L., Arecácea):

"Ser mortal como tú nunca he visto hasta aquí con mis ojos, / ni mujer ni varón: el asombro me embarga al mirarte; / una vez sólo en Delos, al lado del ara de Apolo, / una joven palmera advertí que en tal modo se erguía. / Cuando allí vine a dar, larga hueste escoltaba mis pasos / en jornada que había de traerme dolor y desgracias; / y al hallar aquel tronco gran rato quedé sorprendido / entre mí, porque nunca otro igual se elevó de la tierra. / Con el mismo estupor, ¡oh mujer!, contemplándote estoy..." (Od. VI 160-168).

Puesto que sus compañeras se han asustado y han huido del náufrago, Nausícaa se ha quedado sola ante Odiseo y su cuerpo de muchacha tiene la misma gracia y esbeltez de una joven palmera. También ella ha crecido como ejemplar único entre los de su especie.

El PAISAJE CULTURAL: BOTÁNICA DE LA COTIDIANIDAD Como ya lo enfatizara Forster (1936), las plantas intervenidas culturalmente son siempre las más sobresalientes. También los paisajes culturales generados por la actividad humana son descritos con gran precisión por Homero, - sean campos de cultivo, praderas ganaderas, huertos frutales u hortícolas, viñedos; sean jardines, alamedas o bosques consagrados a los dioses. Las actividades de subsistencia reseñadas en la obra son principalmente las agro-pastoriles. La Fig. 2 muestra que la proporción de plantas alimenticias y forrajeras corresponde a un $21 \%$ del total de los tipos de relaciones destacadas en Homero. Entre las plantas cultivadas destacan por su importancia alimenticia y simbólica los cereales y la vid, cuya mención conjunta equivale a cerca de un tercio del total de las referencias botánicas de la obra (Fig. 1). En la agricultura de la época ocupa un lugar central la producción de cereales, de la familia Poáceas, como la cebada, gr. krithē
(Hordeum vulgare), el trigo, gr. pyrós (Triticum aestivum L.) y la espelta, gr. zeiá (T. monococcum L.). Un lugar relevante corresponde al trigo y la cebada, que en conjunto abarcan un 14\% de las referencias botánicas homéricas (Fig. 1). Estos cultivos proveen el grano para preparar harina y pan (álphiton): "En total doce siervas molían las harinas de trigo y cebada, vigor de varones" (Od. XX 107-108). Comer pan es el símbolo de civilización en la comunidad de la época. Como se reseña después, estos cereales son sagrados y se ofrecen en los ritos ceremoniales.

Entre las hortalizas, se menciona la cebolla, gr. krómmyon (Allium cepa L., Amarilidácea), y dos legumbres de la familia Fabáceas: el garbanzo, gr. erébinthos (Cicer arietinum L.) y el haba, gr. kýamos (Vicia faba L.); en los huertos frutales, Rosáceas, como el peral, gr. ónchnē (Pyrus communis L.) y el manzano, mēléa (Malus domestica Boskh.); el granado, gr. rhóa (Punica granatum L., Lythraceae); la higuera, gr. sykéa (Ficus carica L., Morácea) y el olivo cultivado, gr. elaia. La variada producción frutícola de la época aparece en la descripción de uno de los más afamados jardines en la literatura post-homérica, el huerto de Laertes. En el episodio de reencuentro de Odiseo con su padre, Laertes pone a prueba la identidad de su hijo y este aduce como evidencia sus recuerdos de la niñez: nombra y enumera todos los árboles del huerto que, alguna vez, Laertes le regalara:

"Pero voy además a contarte los árboles todos / que me diste una vez de esta huerta florida. Yo, aun niño, / caminaba contigo por ella, te hacía mil preguntas, / tú mostrabas las plantas y me ibas diciendo sus nombres; / diez manzanos y trece perales me diste, de higueras / hasta cuatro decenas; de liños de vides contaste / medio ciento también para mí: producía cada liño / sin cesar -aún en ellos hay gajos de todas sazones- / según iban viniendo de arriba los tiempos de Zeus" (Od. XXIV 336-344).

Merecen un énfasis especial las detalladas distinciones y descripciones relacionadas a uno de los cultivos más significativos, desde la perspectiva simbólica, la vid, ámpelos (Vitis vinífera L., Vitácea). Así, se consignan con nombres propios los racimos de uva, staphylé; los viñedos, alōé; las uvas inmaduras, ómphax (ver Catálogo). En la Figura 1 se observa que las referencias a uvas y viñas corresponden a un $14 \%$ del total de menciones. La vid es una de las plantas sagradas de Dionisos, el dios de la embriaguez divina, como lo son también la hiedra, la higuera y el pino. En la Ilíada (VI 130-137) se consigna por primera vez el culto del dios del delirio -acosado por Licurgo y protegido en el mar por Tetis-, pero no se le reconoce como el dios del vino, como en los poemas y relatos posteriores. De acuerdo con Otto 1960 (p.109), el vino es una metáfora del propio dios 
"surgido de «la madre salvaje», como dice Esquilo, «ígneo bebedizo de la negra madre», como lo llama Eurípides".

Un ejemplo de la alimentación de la época es la mesa que se ofrece a Patroclo en la tienda de Néstor: "Primero puso delante a cada uno de los dos una mesa bella [...] luego sobre ella una broncínea cestilla, cebolla como companaje para la bebida y amarillenta miel; al lado, molienda de sacro trigo" (Il. XI 628-631). También en la obra se describen las faenas asociadas a la producción agrícola, como la vendimia, la siembra, la siega, la cosecha, la preparación de alimentos, molienda de trigo, producción de vino, etc.; asimismo, las herramientas e instalaciones necesarias, como arados, cercos o barandales, liños o hileras de vides, etc. (el mejor ejemplo de labores y paisajes agropecuarios se encuentran en el famoso escudo de Aquiles, Il. XVIII 541-589).

En la descripción de los paisajes agro-pastoriles y sus pastizales, Homero destaca las especies vegetales propias de las praderas y otros hábitats húmedos, adecuadas para la crianza de caballos, como juncia, trébol, espelta, cebada, loto y apio palustre, gr. sélinon (Apium graveolens L., Apiácea $)^{16}$ : "Los caballos, cada uno junto a su carro, estaban ronzando el loto y el palustre apio" (Il. II 775-776). Una distinción entre paisajes culturales aparece en la Odisea, cuando Telémaco compara las yermas y empinadas llanuras caprinas de sus islas natales con las fértiles y húmedas praderas de las tierras de Menelao, apropiadas para cultivos de cereales, plantas forrajeras, crianza de caballares y otras actividades agropecuarias:

"Tú mandas en una campiña / dilatada donde hay mucho trébol, y juncia abundante, / buenos trigos y espeltas y blancas y óptimas cebadas. / Allá en Ítaca faltan praderas, caminos: es tierra / para cabras, más digna de amor que la rica en caballos; / en las islas abiertas al mar los corceles no tienen / donde corran ni pazcan, y en Ítaca menos que en otras" (Od. IV 602-608).

Entre las plantas usadas en la alimentación de los cerdos figuran los frutos secos y las bayas de árboles silvestres, como las bellotas (bálanos) ${ }^{17}$, los frutos de las encinas;

\footnotetext{
${ }^{16}$ Probablemente se trate del "perejil o apio del caballo" (Smyrnium olusatrum L., Apiácea), del gr. hipposelinon. Teofrasto (HP VII, 6, 3-4), distingue dos especies silvestres de apio, parecidas al apio cultivado (Apium graveolens L.): "El apio que crece a orillas de los canales de riego y en los pantanos tiene escasas hojas y no es basto, sino que se asemeja algo al apio cultivado en olor, gusto y aspecto. El apio caballar tiene las hojas parecidas a las del apio de los pantanos".

${ }^{17}$ La palabra bálanos según Merry et al. 1886-1901 es el fruto de phēgós (Quercus macrolepis T. Kotschy). En numerosas secciones y libros de la obra de Teofrasto, bálanos es el fruto de drys y de phēgós, es decir, de las especies de encinas en general (Quercus), frutos secos llamados bellotas en español.
}

los hayucos $(\text { akylos })^{18}$, posiblemente frutos de Fagáceas o Aquifoliáceas; y las bayas del corno, kráneia (Cornus mas L., Cornácea): "Dábales Circe / de alimento bellotas y hayucos y bayas de corno, / cuales comen los cerdos que tienen por lecho la tierra" (Od. X 241-243). Para las mulas, las gramas ${ }^{19}$ (gr. agrostis) y pastos en general: "Al llegar descargaron las mulas del peso del yugo / y dejaron que a orillas del río de mil remolinos / se saciasen de gramas sabrosas" (Od. VI 8889). Como forraje para los caballos se menciona el trigo y la cebada: "Desuncieron del carro a los potros que al yugo sudaban / y al pesebre lo fueron a atar, donde echaron el trigo; / a sus granos mezclaron después los de blanca cebada / y arrimaron el carro al tapial reluciente del fondo" (Od. IV 39-42). "Cuando llegaron a la bien fabricada tienda del Tidida, ataron los caballos con bien curtidas correas al equino pesebre, donde ya los caballos de Diomedes, de ligeros cascos, estaban comiendo trigo, dulce como miel" (Il. X 566-569). En los húmedos pastizales, los caballos "estaban ronzando el loto y el palustre apio" (Il. II 776).

Los ecosistemas de bosques son la principal fuente de materiales técnico-artesanales que proporciona la flora. En la Figura 2 se destaca la importancia de las plantas en construcción y artesanías, con una proporción de 15\% del total de rubros de utilización. Los grandes árboles tienen uso múltiple, destacando las maderas de una serie de especies nativas, especialmente las muy duras de las Coníferas, como el pino, el abeto, el cedro, el ciprés, apropiadas para la edificación de casas, embarcaciones, herramientas y construcciones menores (ver Catálogo). Un magnífico

\footnotetext{
${ }^{18}$ Es difícil la elucidación del término akylos. De acuerdo con Liddell et al. 1989, es la bellota de Quercus ilex. Merry et al. 1886-1901 consideran que akylos "is probably the berry of the Ilex, according to Pliny, NH 16. 8”. El acebo, Ilex aquifolium L. (Aquifoliáceas), posee bayas carnosas (berry) que alimentan aves y otros animales. En latín, la palabra ilex designa una especie de encina (Quercus ilex) de fruto seco, con hojas enteras en plantas adultas y ramas altas y dentadoespinosas, similares al "acebo" (Ilex aquifoliun), en plantas jóvenes arbustivas. La semejanza entre las hojas espinosas del acebo con las hojas juveniles de $Q$. ilex, y que los frutos de ambas sean alimento de animales, hacen difícil discernir cuál es la especie consignada por Homero con palabra akylos. En Naturalis Historia XVI, 19, Plinio dice que hay dos géneros de ilex: una con hojas enteras parecidas a la del olivo y otra de hojas espinosas (aquifoliae). El fruto de ambas especies sería más grácil y Homero lo llamaría akylos, para distinguirlo de la bellota común (bálanos). Estos dos "géneros" de Plinio podrían corresponder: (i) a las dos subespecies de Quercus ilex: subsp. ilex, de hojas enteras, y subsp. ballota, de hojas algo espinosas; (ii) o bien, a dos especies con hojas espinosas parecidas: Quercus ilex subsp. ballota y/o Ilex aquifolium. Finalmente, la palabra española hayuco consigna el fruto del haya, Fagus sylvatica L. (Fagácea), del cual dice Teofrasto (HP III, 10, 1): "El fruto es terso como una bellota, encerrado en una cáscara que carece de púas". Plinio el Viejo (NH XVI, 25) comenta: "Al puerco le gusta mucho la bellota del haya".

${ }^{19}$ En español la palabra "grama" refiere a Poáceas, en general. La palabra griega usada por Homero es agrostis, una especie de Poácea en particular, Cynodon dactylon (L.) Pers.
} 
ejemplo del uso de materiales vegetales en construcción y artesanías se expone en la Odisea. Entre las maderas utilizadas en la construcción del palacio de Odiseo en Ítaca se mencionan las maderas de fresno, ciprés, abeto y encina; ellas se usan para los pisos, quicios de puertas y vigas del techo: "Tras la puerta se echó en el umbral de madera de fresno, / reclinado en el quicio que un hábil artista hizo antaño / ciprés y pulido erigió regulándolo a cuerda" $(O d$. XVII 339-341). "Las paredes, las bellas pilastras de toda esta pieza, / las columnas que al techo se alzan, las vigas de abeto" (Od. XIX 37-38). "Dirigióse a aquel suelo de encina en que antaño un experto / constructor, tras pulirlo y reglarlo a cordel, los dos postes / levantó para luego ajustar las espléndidas puertas" (Od. XXI 43-45). El papiro, gr. byblos (Cyperus papyrus L., Ciperácea), cuya fibra es usada para el cordaje de los navíos, sirve como amarra del portón del palacio: "Y cerró el gran portón en el patio de sólidos muros; / por el suelo vio un cable de combo navío / bien trenzado en papiro; con él amarró las dos hojas" (Od. XXI 389-391).

Asimismo, la madera para la construcción de embarcaciones y balsas, y las herramientas e instrumentos asociados, es proporcionada principalmente por los elevados árboles nativos, especialmente Coníferas, como el ciprés y el abeto. Como se destaca después, la propia ninfa Calipso tutela la búsqueda de los hábitats especiales, con potentes troncos de maderas envejecidas, apropiadas para la fabricación y flotación de la barca de Odiseo: alisos, chopos $\mathrm{y}$ abetos $^{20}$. También la diosa proporciona las herramientas adecuadas para este trabajo, que incluyen materiales vegetales como el olivo. La madera usada para el mástil y los remos es de abeto: "En la hueca carlinga encajaron el mástil de abeto" (Od. II 424; XV 289). El revestimiento, de zarcillos de mimbre: "Cercándolo todo con zarzos de mimbre, defensa / de la fuerza del agua, lastró con madera abundante" (Od. V 256-257). En la Ilíada se menciona para la fabricación de quillas el uso del pino "que en los montes los carpinteros talan con recién afiladas hachas para convertirlo en quilla" (Il. XVI 483-484).

La madera de arbustos y árboles pequeños se usan en construcciones menores, como estacas para portones, cercos de huerta; también para medios de transporte, como carros y carretas. Entre las especies utilizadas destaca la madera de abeto; álamo negro; cabrahigo, gr. erineós (Ficus carica L. subsp. rupestris, Morácea); y boj, gr. pýxos (Buxus sempervirens L., Buxácea); las cañas; también los tallos flexibles de los mimbres. Para estacas de cercas se utiliza la encina: "larga fila de estacas que hachó de unos troncos de encina" (Od. XIV 13). El espino, gr. ácherdos (Pyrus amygdaliformis Vill., Rosácea), se usa como barda encima

\footnotetext{
${ }^{20}$ Es digno de destacar que con abeto construyeron los aqueos, según nos cuenta Virgilio (Eneida II, 16), el famosísimo caballo de Troya (texto latino de Hirtzel 1900).
}

de las tapias donde se guardan los cerdos. La techumbre de la tienda de abeto de Aquiles en el campamento aqueo era de cañas:

"Cuando llegaron a la tienda del Pélida elevada, que los mirmidones habían fabricado para su soberano tallando vigas de abeto - por encima la habían techado con frondoso cañizo recolectado de la pradera; alrededor un gran patio habían fabricado para su soberano con espesas estacas; la puerta la sujetaba un único pasador de madera de abeto, que entre tres aqueos solían encajar" (Il. XXIV 449454).

Para carros y carretas se destacan los materiales para fabricar barandas y ruedas. "Con el afilado bronce un cabrahigo desmochaba de ramas nuevas para hacer la baranda de un carro" (Il. XXI 37-38). El álamo negro "que el carretero tala con el fogueado hierro para curvarlo como llanta para un carro" (Il. IV 485-486). Para yugos, el boj:

"Sacaron una carreta de mulas, de buenas ruedas, bella, por primera vez claveteada, $\mathrm{y}$ ataron encima un cesto de mimbres. Descolgaron del clavo el yugo para las mulas, de madera de boj, provisto de un resalte, bien ajustado con anillos" (Il. XXIV 266-269).

En la fabricación de armamentos, como flechas, lanzas y picas, la especie más importante es el fresno ${ }^{21}$. Como se dijo antes, su nombre es citado numerosas veces en relación con este uso específico o para nombrar, por metonimia, la "lanza" (ver Catálogo): "Asaltábanme muchos con sus lanzas de fresno" (Od. XIV 281-282); "y enarboló la pica de fresno" (Il. V 655); "y de su muslo extrajo la lanza de fresno" (Il. V 694); "Sólo Aquiles era capaz de blandir la pelíada lanza de fresno que Quirón había procurado a su padre" (Il. XVI 142-143; XIX 390). Incluso el fresno sirve como epíteto, por ejemplo, en el apelativo de Príamo como "el de buena lanza de fresno" (Il. VIII 552).

En la fabricación de herramientas y mueblería sobresale la madera de olivo: "Le entregó una gran hacha de bronce adaptada a sus manos / con sus cortes agudos a un lado y a otro y cogida / a un astil bien labrado de olivo con sólido ajuste" (Od. V 234-236). En el mobiliario doméstico, la fabricación de la cama nupcial de Odiseo es uno de los textos más detallado y bello que ilustra el uso de la madera de olivo. Merece destacarse la causa de esta pormenorizada descripción: Penélope, para saber si el hombre que se ha presentado como Odiseo es realmente su marido, lo pone

\footnotetext{
${ }^{21}$ Según explica Grimal 1951, las melíades, ninfas de los fresnos, nacieron de la sangre vertida durante la mutilación de Urano, lo que explica el hecho de que las lanzas homicidas se fabrican con madera de fresno (1997, sub voce "Melíades").
} 
a prueba diciendo a las esclavas que saquen la cama de la habitación. Odiseo, asombrado por ese pedido, describe cómo construyó su propio tálamo en un olivo in situ, tálamo que, por lo tanto, no puede ser movido:

"Un olivo de gráciles hojas se alzaba en el patio, / floreciente, crecido, como una columna de grueso / en su tallo; y en torno de éste con piedras bien juntas / levanté mi aposento, cubrílo con un buen tejado / y le puse unas puertas trabadas de sólido ajuste. / Corté luego el ramaje al olivo de gráciles hojas / y mondé de raíz para arriba su tronco, pulido / lo dejé por el bronce con arte y destreza, reglélo / a cordel como pata de cama, le abrí los taladros / y empezando por ello hice el lecho completo que luego / revestí con marfil, oro y plata, y al fin sus costados / con correas uní de buen cuero teñidas de rojo" (Od. XXIII 190-201).

También son importantes los tallos duros y flexibles que proporcionan fibras vegetales para atar materiales o confeccionar sogas, nudos, cestería y muebles. Sobresalen los tallos de los mimbres, gr. lýgos (Vitex agnus-castus L., Verbenácea): "Desgajando después unas ramas de zarzas y mimbres / una cuerda trencé de una braza de largo" (Od. X 166-167); "Una vez Aquiles en las lomas del Ida los había atado [a los hijos de Príamo] con tallos de mimbreras al sorprenderlos pastoreando ovejas" (Il. XI 105); “mandó a preparar y atar encima un cesto de mimbres" (Il XXIV 190). En la Odisea (V 256) aparece otra palabra para consignar el mimbre, oisýa. Probablemente se trate de alguna especie de Salix, género que incluye también varias especies con tallos flexibles muy usados artesanalmente ${ }^{22}$. Entre las fibras textiles destaca el lino, gr. linon (Linum usitatissimum L., Linácea) la planta paradigmática para confeccionar vestuario, enseres de cama, cojines y tejidos varios. En la Odisea se dice que: "le tendieron a Ulises un lecho con lienzos de lino" (XIII 73). En la Ilíada se menciona la "coraza de lino" de dos guerreros (Il. II 830) y también hay cubiertas de cama de este material: "Dóciles extendieron el lecho tal y como había encargado, pieles de oveja, sábanas y delicadas telas de fino lino" (Il. IX 660-661).

Para concluir con la reseña de las distintas clases de relaciones establecidas por Homero en el dominio vegetal, es interesante resaltar la función de las plantas como referentes espaciales. Las indicaciones que proporciona la flora para

\footnotetext{
${ }^{22}$ Teofrasto (HP III, 13, 7) destaca la aptitud del sauce negro (Salix amplexicaulis) para labores de cestería. De acuerdo con este autor, hay una variedad de sauce que crece pequeña y que los habitantes de Arcadia llaman "mimbrera". Probablemente se trate de Salix fragilis L. o S. viminalis L., esta última una especie de lugares húmedos que proporciona el mejor mimbre para construcción y artesanías.
}

orientarse, defenderse o instalarse en el espacio bélico son muy importantes en la Ilíada. Un excelente ejemplo lo constituyen las señales que proporciona la vegetación que crece en las llanuras que circunda la ciudadela de Troya, poblada de cabrahígos, como asimismo la encina próxima a sus puertas Esceas. Ambas especies son los referentes vegetales más importantes en el espacio bélico de la Ilíada, ya que indican a los combatientes troyanos, tanto el área que requiere la más fuerte defensa, como asimismo la cercanía protectora de los muros de la ciudad. Es ilustrativo el siguiente pasaje de la Ilíada:

"En medio de la llanura, más allá del cabrahígo se precipitaban (los troyanos) ávidos de refugiarse en la ciudad. Voceando sin cesar el Atrida los acosaba y salpicaba de mortandad sus inaferrables manos. Pero al llegar a las puertas Esceas y a la encina, allí se detenían y unos a otros se aguardaban a pie firme" (Il. XI 167-170).

La encina próxima a las puertas Esceas es mencionada cuatro veces como referencia formular en la contienda (Il. VI 237, IX 354, XI 170; XXI 549). En este mismo contexto, el cabrahígo es asimismo aludido cuatro veces como señal (Il. II 793; VI 433, XI 167, XXII 145): “Detén a la hueste junto al cabrahígo, donde más accesible es la ciudad y la muralla más expugnable ha resultado" (Il.VI 433). "Más allá de la atalaya y del ventoso cabrahígo pasaron" (Il. XXII, 145). Un tronco muerto muy especial también puede indicar el punto de retorno en una competencia:

"La señal está bien visible; te la diré y no se te olvidará: es un tronco seco, que se eleva como una braza desde el suelo, de encina o de pino, que no se pudre con los aguaceros y al que dos piedras blancas a cada lado sirven de apoyo en la encrucijada del camino, y la pista es lisa a ambos lados" (Il. XXIII 326-330).

Finalmente, habría que decir que las plantas homéricas cumplen también otras funciones variadas, además de las descritas, sea como combustible o adorno, sea en relaciones accidentales, tales como apoyo, refugio ante peligros, marca de escondites, etc. Así, la madera de Coníferas es apreciada por sus aromas balsámicos, especialmente las resinas aromáticas del cedro y el alerce africano, $\mathrm{y}$, asimismo, como leña: "Derecho / caminó hacia la cueva espaciosa, mansión de la ninfa [Calipso] / de trenzados cabellos. Allí estaba ella, un gran fuego / alumbraba el hogar, el olor del alerce y del cedro / de buen corte, al arder, aromada dejaban la isla / a lo lejos" (Od. V 56-61); "Luego entró en el tálamo perfumado de madera de cedro" (Il. XXIV 191).

Hay pocas referencias al uso estético-ornamental de las plantas en Homero. Un ejemplo de ornamento con motivos botánicos es: "un caldero intacto por el fuego y adornado 
con flores" (Il. XXIII 885). En la flora homérica sorprende la ausencia de un taxon que, por su hermosura, habrá de tener especial importancia en la lírica arcaica posterior y en toda la lírica occidental: la rosa, gr. rhódon (Rosa gallica L., Rosácea). En Homero se encuentra mencionado una sola vez el adjetivo rhodoeís ("de rosa") para calificar el aceite con que Afrodita unge el cuerpo de Héctor (Il. XXIII 186) ${ }^{23}$. Más allá de su valor ornamental, la magnificencia de las flores está asociada principalmente a espacios sagrados, como el delicado jardín con violetas, gr. íon (Viola odorata L., Violácea) de la ninfa Calipso; o la alameda y el bosque de Atenea, en el jardín mítico de tierra de feacios; o el lecho de Zeus y Hera, suavizado con frescas hierbas y bellas y fragantes flores, como el azafrán, gr. krókos (Crocus sativus L. ${ }^{24}$, Iridácea) y el jacinto, gr. hyákinthos (Hyacinthus, Asparagácea): "Bajo ellos la divina tierra hacía crecer blanda yerba, loto lleno de rocío, azafrán y jacinto" (Il. XIV 348).

Ejemplos de la protección de los árboles se ofrece cuando Aquiles, arrastrado por la corriente del río Escamandro, "se asió con ambas manos a un olmo alto y corpulento, que, al desplomarse entonces de raíz [...] frenó la bella corriente con sus frondosas ramas y tendió un puente sobre el propio río" (Il. XXI 242-245); o cuando Odiseo dice que, huyendo de Caribdis, "dando un salto en el aire colguéme del gran cabrahígo" (Od. XII 432); a veces los árboles refugian a los propios dioses, como a Sueño quien, escapando a los ojos de Zeus, "trepó a un abeto gigantesco" (Il. XIV 287); También las plantas pueden oficiar de escondrijo, como cuando Odiseo marca y oculta en un tamarisco, gr. myrike (Tamarix tetrandra Pall. ex Bieb., Tamaricácea) los trofeos arrebatados en la contienda: "los depositó en lo alto de un tamarisco y puso un nudo como señal, entrelazando cañas y muy florecientes ramas de tamarisco" (Il. X 466-467) ${ }^{25}$.

\section{RASGOS MÍTICOS EN LA VISIÓN DE LA VEGETACIÓN}

Los elementos míticos atraviesan transversalmente la geografía botánica de Homero, sea en las características sobrenaturales que se adscriben a ciertas comunidades vegetales, tanto silvestres como cultivadas; sea en la atribución de poderes mágico-terapéuticos a ciertas plantas; sea en la personificación de los elementos y fenómenos naturales transformados en dioses; sea en el uso de plantas sagradas en rituales y ceremonias; sea en la constante intervención y tutela divina en procesos naturales $\mathrm{y}$

\footnotetext{
${ }^{23}$ Por lo demás, la palabra rosa aparece en el compuesto rhododáktylos (dedos de rosa), recurrente epíteto de Eos, la Aurora.

${ }^{24}$ De acuerdo con Segura \& Torres 2009 (p. 324), Crocus sativus es la única flor que los griegos y romanos aclimataron en época histórica.

${ }^{25}$ También hay situaciones accidentales o molestas relacionadas con plantas como "enredarse en la rama de un tamarisco y romper el corvo carro" (Il. VI 39) o espinar el cuerpo y las manos, como es el caso de la zarza, gr. bátos (Rubus ulmifolius, Rosaceae).
}

actividades técnico-artesanales. En la Figura 2 se aprecia que las referencias míticas corresponden a un 13\% del total de las relaciones consideradas.

Los extraños escenarios del largo itinerario del retorno de Odiseo a su isla de Ítaca, después de la caída de Troya, constituyen el mejor ejemplo de una geografía mítica. Un extenso espacio marítimo de fronteras indefinibles donde se suceden, de isla en isla, una serie de mundos no humanos, poblados de seres fabulosos que no comen pan, que no saben de sociabilidad ni de hospitalidad: monstruos como Caribdis; lotófagos, comedores de flores; gigantes caníbales, como legistrones y cíclopes; ninfas y hechiceras como Calipso y Circe; peligrosas sirenas; vacas sagradas e inmortales, pertenecientes al dios del sol; praderas en tinieblas donde se encuentran las almas de los muertos. Todos estos entes habitan mundos idílicos, cercanos a la naturaleza silvestre, con bosques, ríos y bellas playas.

La bisagra entre estos mundos fabulosos y el mundo humano es la tierra de los feacios, un pueblo feliz que habita un lugar geográfico no identificado, gobernado por el rey Alcínoo, miembro de un linaje sagrado protegido por los dioses. Precisamente, uno de los más minuciosos y bellos relatos de espacios vegetales sobrenaturales es la descripción del jardín y palacio de los feacios. Entre los dones divinos recibidos por Alcinoo se incluyen jardines ${ }^{26}$ y tierras cultivadas con una vegetación eternamente productiva e intemporal. Todos los procesos biológicos y las etapas del ciclo anual de crecimiento, desarrollo y maduración de los árboles frutales, viñedos y verduras de los huertos son sincrónicos en ese jardín sobrenatural: generación, floración, maduración, senectud, también la cosecha; ello es descrito primorosamente cuando se cita la presencia simultánea de las diferentes fases de maduración de la uva en esas viñas divinas:

"Por de fuera del patio se extiende un gran huerto, cercadas / en redor por un fuerte vallado sus cuatro fanegas; / unos árboles crecen allá corpulentos, frondosos: / hay perales, granados, manzanos de espléndidas pomas; / hay higueras que dan higos dulces, cuajados, y olivos. / En sus ramas jamás falta el fruto ni llega a extinguirse, / que es perenne en verano e invierno; y al soplo continuo / del poniente germinan los unos, maduran los otros: / a la poma sucede la poma, la pera a la pera, / el racimo se deja un racimo y el higo otro higo. / Tiene Alcínoo allí mismo plantada

\footnotetext{
${ }^{26}$ De acuerdo con Martínez 2008, los poemas homéricos son los primeros testimonios literarios de los jardines de la época heroica. El autor documenta que el jardín de los feacios se convirtió en proverbial en la literatura post-homérica, especialmente en la latina, y cita a Plinio el Viejo, Propercio, Ovidio y Marcial, entre los autores que lo elogian.
} 
una ubérrima viña / y a su lado se ve un secadero en abierta explanada / donde da recio sol; de las uvas vendimian las unas / mientras pisan las otras; no lejos se ven las agraces / que la flor han perdido hace poco o que pintan apenas. / Por los bordes del huerto ordenados arriates producen / mil especies de plantas en vivo verdor todo el año. / Hay por dentro dos fuentes: esparce sus chorros la una / a través del jardín y la otra por debajo del patio / lleva el agua a la excelsa mansión donde el pueblo la toma. / Tales son los gloriosos presentes que el cielo da a Alcínoo" (Od. VII 112-132).

Otro ejemplo de una comarca fabulosa, donde todos los procesos naturales son dirigidos por los dioses, es la isla de los Cíclopes -gigantes que no cazan, ni labran la tierra-. La naturaleza silvestre les proporciona, espontáneamente y sin esfuerzo de trabajo, todo lo que requieren para vivir y alimentarse: el agua, los vientos favorables, los puertos adecuados, los prados, los bosques, las plantas y el ganado para alimentarse. No necesitan herramientas, ni técnicas para cultivar la tierra o construir casas o navegar: viven en grutas y todo lo que demandan para subsistir se los ofrece naturalmente el entorno. Con tan pródiga dádiva divina, tampoco requieren de leyes para regular la convivencia, ni comercian con otros hombres:

"Seguimos bogando / hasta dar con la tierra que habitan los fieros cíclopes, / unos seres sin ley. Confiando en los dioses eternos, / nada siembran ni plantan, no labran los campos, más todo / viene allí a germinar sin labor ni simienza: los trigos, / las cebadas, las vides que dan un licor generoso / de sus gajos, nutridos tan sólo por lluvias de Zeus" (Od. IX 105-111).

En el contexto mítico en que se desarrolla la obra de Homero, la potencia curativa o tóxica de las pocas plantas medicinales registradas ${ }^{27}$ procede siempre de la sabiduría de dioses o semidioses. Quizás la mejor ilustración de los poderes mágico-terapéuticos de algunas especies botánicas es relatada en la Odisea, cuando la hechicera Circe, administra una tóxica $\operatorname{droga}^{28}$ a los compañeros de Odiseo;

\footnotetext{
${ }^{27}$ Es curioso que la obra de Homero mencione tan pocas plantas medicinales o tóxicas, muy importantes en la farmacopea de numerosas etnias. Un ejemplo es la droga con que Helena mezcla el vino de Telémaco y Menelao, para aliviar sus penas: "La nacida de Zeus guardaba estos sabios remedios: / se los dio Polidamna, la esposa de Ton el de Egipto, / el país donde el suelo fecundo produce más drogas / [...] todos los hombres allí son expertos / como nadie en curar, porque traen de Peán su linaje" (Od. IV 227-232).

${ }^{28}$ Pastor \& Cuesta 2004, sobre la base de la literatura etnohistórica, postulan que la hierba administrada por Circe para drogar a los
}

ésta les borra los recuerdos, los convierte en cerdos, y como tales se comportan:

"Ya en la casa los hizo sentar por sillones y sillas / y, ofreciéndoles queso y harina $\mathrm{y}$ miel verde y un vino / generoso de Pramno, les dio con aquellos manjares / un perverso licor que olvidar les hiciera la patria. / Una vez se lo dio, lo bebieron de un sorbo y, al punto, / les pegó con su vara y llevólos allá a las zahúrdas; / ya tenían la cabeza, y la voz y los pelos de cerdos / y aún la entera figura, guardando su mente de hombres" (Od. X 233-240).

Más interesante aún que la extraña metamorfosis que suscita la droga de Circe es el poder mágico-terapéutico del antídoto para la misma que se le proporciona a Odiseo. Éste relata que el órgano subterráneo de una planta ${ }^{29}$ llamada môly le fue entregada por el propio dios Hermes, para conjurar los efectos de eventuales fármacos que le administraría la

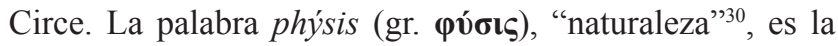
usada por Hermes para referirse a las cualidades naturales y poder de la planta môly:

"Entonces, [una vez que habló] así, el Argifonte le entregó un fármaco, / que extrajo de la tierra, y le mostró su naturaleza. / Era negra en la raíz, pero su flor era semejante a la leche. / Los dioses la llaman moly. Es difícil extraerla / para los hombres mortales, pero lo dioses todo lo pueden" (Od. X 302-306. Trad. propia).

compañeros de Odiseo podría relacionarse con: (i) el género Circea (Onagrácea), nombre talvez derivado del de la diosa Circe, descrita por Dioscórides en De Materia Medica CXXVIll, 349); (b) la Mandrágora (Mandragora autumnalis L., Solanácea) que, según Teofrasto (HP IX, 9, 1), Dioscórides ( $M M$ IV, 75) y Plinio ( $N H$ XXV, 94), algunos llaman Circea porque su raíz se usa para hechizos, como los que practicaba Circe. Como muchas Solanáceas, esta última planta es muy tóxica y contiene potentes alcaloides que bloquean los receptores de la acetilcolina, inhibiendo los impulsos nerviosos, y en dosis elevadas, produce delirio y locura.

${ }^{29}$ Es interesante que las medicinas homéricas se obtengan siempre de los órganos subterráneos de las plantas, costumbre al parecer extendida posteriormente en Grecia, a juzgar por el extenso uso de raíces, bulbos y rizomas medicinales que documenta Teofrasto (HP IX, 8-20). En la Ilíada hay una referencia a la curación con raíces, cuando Eurípilo pide a Patroclo: "Extráeme la flecha del muslo, la oscura sangre que brota de él lávame con agua tibia y espolvorea encima benignas medicinas curativas, remedios que dicen que has aprendido de Aquiles, a quien enseñó Quirón, el más civilizado de los Centauros" (Il. XI 829-832). El dolor cede, la herida se cierra y se detiene la hemorragia con el macerado de "raíz amarga" (gr. rhíza pikré) que Patroclo le administra.

${ }^{30}$ En este verso de Homero es mencionado por primera vez un término fundamental en la episteme occidental: "naturaleza", phýsis. Más allá de su acepción de atributo natural con que lo usa Homero, la palabra adquiere con posterioridad una connotación conceptual muy compleja en la filosofía griega. 
En los versos citados, Odiseo describe las características de la planta llamada môly por Hermes, usando el lenguaje coloquial ordinario. La eventual concordancia entre esta descripción y los atributos de distintas especies semejantes, consignadas con diversos nombres latinos, ha sido establecida por varios autores posteriores. Según Teofrasto, el "ajo negro" (Allium nigrum L., Amarilidáceas) se asemejaría al môly: "Dicen que es semejante a aquel al que se refiere Homero. Tiene la raíz redonda, semejante a una cebolla [...]. Se hace uso de ella, según dicen, contra los hechizos y las artes mágicas. Pero no es difícil, como pretende Homero, sacarla de la tierra" (HP. IX, 15, 7). De acuerdo con la información etnográfica y morfología comparada, Pastor \& Cuesta (2004) proponen otras dos especies de Allium (A. subhirsutum L., A. neapolitanum Cirillo) que se ajustarían a los atributos presentados para el môly. Plaitakis \& Duvoisin 1983 proporcionan evidencias bioquímicas que apoyan la hipótesis de que la planta môly que Hermes ofrece a Odiseo podría corresponder a Galanthus nivalis L. (Amarilidáceas). El nombre latino de la especie alude al color blanco de las flores (del gr. gála, "leche" y ánthos, "flor") y a su crecimiento en pleno invierno (del lat. nivalis "de la nieve") ${ }^{31}$. La especie está provista de bulbos subterráneos, difíciles de extraer, y contiene alcaloides. Todas estas características concuerdan con la naturaleza de la planta descrita por Homero. De acuerdo a los autores, la especie contiene galantamina, una enzima anticolinesterásica, que actúa a nivel del sistema nervioso central; éste compuesto podría haber actuado como antídoto ante la eventual intoxicación de Odiseo, provocada por las drogas administradas por Circe. En definitiva, hay una alta probabilidad de que el môly sea una especie de la familia Amarilidácea: la fitoquímica, la dificultad para extraerla de la tierra y la ausencia de "olor aliáceo" ${ }^{32}$ favorecen al género Galanthus.

Otra mención acerca de poderes sobrenaturales de las plantas figura en el episodio de los lotófagos "gente que sólo de flores se alimenta" (Od. IX 84-85). Homero llama "loto" (gr. lōtós) a una planta cuyo fruto, al ser consumido, borra la memoria y los hombres olvidan el regreso a su tierra natal: "Les hicieron su fruto comer. El que de ellos probaba / su meloso dulzor, al instante perdía todo gusto / de volver y llegar con noticias al pueblo paterno" (Od. IX 93-95). Es

\footnotetext{
${ }^{31}$ Teofrasto menciona la "campanilla de invierno" (HP VII, 13, 9), Galanthus nivalis L., pero no la consigna como môly.

${ }^{32}$ La familia Amarilidáceas, comprende: (i) la subfamilia Allioideas, Tribu Allieae, con un sólo género, Allium, con alrededor de 550 especies distribuidas en zonas templadas del Hemisferio Norte, todas ellas con bulbos, muchas comestibles y medicinales, con compuestos con olor a cebolla o ajo, el típico "olor aliáceo"; (ii) la subfamilia Amarilidóideas, también bulbosas, con presencia de típicos alcaloides y ausencia de "olor aliáceo", incluye la Tribu Galantheae, con cinco géneros, comprendido el Género Galanthus con veinte especies, entre ellas G. nivalis.
}

difícil discernir a qué taxon pertenecería este mítico fruto. Como se ha mencionado antes, son consignadas como lōtós varias plantas herbáceas y forrajeras de la familia Fabáceas, con frutos secos (legumbres), pertenecientes a géneros muy extendidos y con muchas especies -como Lotus, Trigonella, Melilotus, Trifolium-. Las plantas aludidas en la descripción homérica, con frutos dulces, carnosos y comestibles, podrían corresponder a árboles, también llamados "lotos", como Ziziphus lotus (L.) Lam. (Rhamnáceas) y Diospyros lotus L. (Ebenáceas). El primero de estos árboles es identificado por Teofrasto (HP 4.3.1-4) y Forster (1936) como el "loto" de los lotófagos.

Como ya lo han documentado varios autores (Bowra 1933, Nestle 1930, 1962, Sesar 1997), los rasgos míticos más arcaicos en el tratamiento de la naturaleza han prácticamente desaparecido en Homero -como el animismo, metamorfosis y totemismo-. Su simbolismo ha sido transferido a la generación de poderosos dioses que cruzan todo el relato homérico, y que se asemejan en aspecto y conducta a los seres humanos. La personificación divina abarca los fenómenos y los diversos componentes de la naturaleza física -por ejemplo, el viento, el océano, la aurora, los ríos, la tierra, el sol, la luna-. El relato más sublime y pormenorizado de personificación divina es la interpelación que el poderoso dios-río Escamandro dirige a Aquiles: "el río, de profundos remolinos, dijo airado con figura humana y emitiendo la voz desde una honda vorágine..." (Il. XXI 212-213). El río arenga a sus afluentes, acrecienta su corriente y persigue encarnizadamente a Aquiles: "Así la onda del río alcanzaba una y otra vez a Aquiles, a pesar de su rapidez: los dioses son superiores a los hombres" (Il IX 263-265) ${ }^{33}$.

Sin embargo, en Homero persisten unos pocos ejemplos de metamorfosis en elementos naturales, que enraízan la obra con el pasado mítico anterior. Se trata de ocasionales transformaciones de los dioses en seres de distinta apariencia, humana, animal o vegetal ${ }^{34}$. Un único ejemplo de transformaciones que incluye una planta es la del Anciano del Mar, el "eterno Proteo" que todo lo sabe, y a quien acude Menelao para conocer el camino de regreso a Ítaca: "Cambióse primero en león melenudo, / en serpiente después, en leopardo y en cerdo gigante, / luego de ello en corriente de agua y en árbol frondoso" (Od. IV 456-458) $)^{35}$. Un caso de animalización es la ya comentada metamorfosis en puercos de los compañeros de Odiseo. Con posterioridad a Homero son frecuentes los mitos que narran metamorfosis

\footnotetext{
${ }^{33}$ Otro ejemplo es el caballo de Aquiles, Janto, divino e inmortal, quien habla con voz humana a su dueño (Il. XIX 405-407).

${ }^{34}$ También Atenea transforma mágicamente a Ulises, sea en un varón más imponente cuando la ocasión lo requiere, sea en un grotesco y anciano pordiosero, cuando quiere ocultarlo mientras planifica su venganza contra los pretendientes de su mujer.

${ }^{35}$ Las metamorfosis son frecuentes en las divinidades acuáticas, quienes, como el agua, son capaces de adoptar distintas formas.
} 
de humanos o semidioses en plantas ${ }^{36}$.

También en Homero está prácticamente ausente el totemismo de los elementos naturales -el culto a las piedras, plantas y animales-. En otras culturas, este es uno de los rasgos característicos del pensamiento mítico asociado al origen de los linajes. En la Odisea hay un rastro del arcaico culto a los árboles en el oráculo de Zeus, mediado por una encina $^{37}$ : el rey Fidón cuenta a Penélope, que se decía que su marido "se hallaba en Dodona inquiriendo de Zeus / a través de la encina copuda del dios cómo era / conveniente que entrase en las tierras de Ítaca al cabo / de una ausencia tan larga" (Od. XIX 296-299) ${ }^{38}$.

En el espacio mítico, además de la inspiración poética y el amparo frente al azote de los elementos naturales, también el beneficio técnico-artesanal de las plantas es revelado por los dioses. Un bellísimo ejemplo es el ya mencionado caso de la ninfa Calipso, quien guía a Ulises en la elección de las maderas y le proporciona las herramientas necesarias para el montaje de su balsa. Esta construcción exige una sofisticada selección de los árboles apropiados -con el tamaño adecuado, dureza conveniente y densidad requerida para la flotación- atributos que poseen solamente algunos nobles ejemplares, procedentes de poblaciones de ciertos

\footnotetext{
${ }^{36}$ Por ejemplo, las Helíades, hijas del Sol, se transformaron en álamos; el joven Croco, en azafrán; la hamadríade Siringe, en caña; el joven Cipariso, en ciprés; el joven Hiacintio, en jacinto; la ninfa Dafne, en laurel; el joven Narciso, en la planta homónima; la joven Plátano, en el árbol homónimo; la princesa Mírice, en tamarisco (cfr. Grimal 1951 sub vocibus "Helíades", "Croco", "Siringe", "Cipariso", "Hiacintio", "Dafne", "Narciso", "Plátano", "Mírice", respectivamente). Según una leyenda, las Hespérides que custodiaban las manzanas de oro, después del robo, se transformaron en un olmo, un sauce y un álamo (cfr. Grimal 1951, p. 249). El dios Apolo está vinculado con numerosos mitos de metamorfosis en flores y plantas (Idem, p. 37).

${ }^{37}$ Homero se refiere a la encina sagrada de Dódona, figura simbólica donde habita Zeus y a quien se le visita como oráculo. El culto a Zeus en el Oráculo de Dódona se remonta a ritos de adivinación centrados en torno a una gran encina sagrada y este ceremonial religioso es uno de los más antiguos -y ha sido evidenciada a partir del II milenio a. C., en conexión con un mito de Hesíodo que relata que el padre de los dioses, Zeus, fue criado en el tronco de una encina-.

${ }^{38}$ Mención aparte merece la oscura expresión en la que se relaciona a la encina con la piedra. Aparece una vez en la Ilíada (XXII 126) con el sentido "¿qué tiene que ver esto con el presente asunto?", en el soliloquio de Héctor: "Más no es momento de remontarse a la encina y a la piedra, ni de charlar con él de las lindezas de una doncella y un mozo". En un sentido semejante se encuentra en Hesíodo, Teogonía 35, cuando el poeta termina de narrar su encuentro con las Musas: "Mas, ¿a qué me detengo con esto entorno a la encina o a la roca?" (Pérez Jiménez \& Martínez Díez 1978). Aparece otra vez en la Odisea (XIX, 163) con el sentido "tú tienes parientes y procedes de un país", cuando Penélope pregunta al mendigo por su linaje: "Mas ¡ea! / dime tú de la raza y país: no naciste, seguro, / de la piedra o la encina que cuenta antiguas historias" (así también se encuentra en Platón: Apología de Sócrates 34d, Calonge 1985, y República 544d, Eggers Lan 1986). Todos estos ejemplos sugieren un uso coloquial de la expresión 'la encina y la piedra'.
}

hábitats especiales. Así relata Homero la tutela de la ninfa en esta selección: "Guióle el camino / a un confín de la isla poblado de troncos gigantes, / con alisos y chopos y abetos que al cielo se erguían, / de madera ya enjuta, propicia a flotar en las aguas" (Od. V 238-240).

Calipso también proporciona las herramientas necesarias: un hacha de bronce con mango de olivo, para talar los árboles; una azuela para pulir la madera; barrenas para taladrar y ensamblar las piezas; y los lienzos para las velas. Más aún, terminada la balsa, le entrega ropas perfumadas, vino, agua, pan, abundantes manjares e incluso "una brisa muy plácida y tibia le dio, favorable" (Od. V 83).

Finalmente, cabe enfatizar en la obra homérica la significativa participación ceremonial de ciertos imponentes árboles -como la encina, el olivo, el sauce, el chopo, el olmo y el plátano- en los cultos rituales, ineludibles en una cosmovisión mítica, por su función simbólica esencial de relacionar al hombre con lo divino. Entre ellos la encina, árbol consagrado a Zeus, ocupa un lugar central. Como ejemplo, cabe destacar que es madera de encina del monte Ida, donde Zeus tiene un bosque consagrado en su honor, la que se tala para la pira mortuoria en el ritual sacrificial que Aquiles tributa al cadáver de Patroclo. De acuerdo con Nestle 1962 (p. 30), este sería un resabio de arcaicos cultos a los muertos: "Fueron cuesta arriba y cuesta abajo, por laderas y en oblicuo, y cuando llegaron a las lomas del Ida, rico en manantiales, empezaron a talar a toda prisa con el bronce, de extendido filo, encinas de elevadas copas" (Il. XIII 116-119) ${ }^{39}$.

Particularmente en la Odisea, el olivo consagrado a Atenea sobresale por su significado simbólico. Así, se recalca varias veces el olivo sagrado del Puerto de Forcis en Ítaca: "Vese al fondo del puerto un olivo de gráciles hojas / y a su lado una cueva sombrosa y amena, recinto / de las ninfas del agua que llaman las náyades" (Od. XIII 102); "Sentóse al pie del olivo sagrado" (Od. XIII, 372). Los chopos y sauces, consagrados a la diosa Perséfone, marcan la entrada al espacio mítico del Hades: "Una extensa ribera hallará con los bosques sagrados / de Perséfona, chopos ingentes y sauces que dejan / frutos muertos" (Od. X 510).

En las ceremonias mortuorias y hecatombes, dedicadas a los dioses, se mencionan árboles como el plátano y el olmo. Así, en la ceremonia que oficia Aquiles después de matar al padre de Andrómaca, se dice que: "Lo incineró con sus primorosas armas y erigió encima un túmulo; $\mathrm{y}$ alrededor plantaron olmos las montaraces ninfas, hijas de Zeus, portador de la égida" (Il. VI 418-419). El plátano (gr.

\footnotetext{
${ }^{39} \mathrm{La}$ encina es también mencionada varias otras veces por Homero en su función tutelar, como la encina frente a las puertas Esceas de Troya. En la Ilíada, Zeus desciende a contemplar la contienda al monte Ida, donde tenía un bosque consagrado en su honor. También Atenea y Apolo se posan como buitres en una encina consagrada a su padre Zeus, "disfrutando con el espectáculo de los hombres" (Il. VII 61).
} 
platánistos o plátanos; Platanus orientalis L., Platanacea), el árbol ornamental predilecto de los griegos ${ }^{40}$, también aparece en la Ilíada con un uso ritual: "y nosotros estábamos alrededor del manantial en sacros altares sacrificando en honor de los inmortales cumplidas hecatombes bajo un bello plátano de donde fluía cristalina agua" (Il. II 305-307).

Entre las plantas cultivadas, los cereales ${ }^{41}$ cumplen un significativo rol en las hecatombes para obtener el favor de los dioses. La cebada (gr. krithē; Hordeum vulgare L., Poácea) es muchas veces nombrada con el epíteto "blanco" (gr. krî leukón, "blanca cebada") y usada ritualmente. La cebada ceremonial, muchas veces es denominada con la palabra, oulochýtai, que alude a los granos de cebada majados o gruesos con que se espolvorea el altar antes del sacrificio: "Con ligereza la sacra hecatombe en honor del dios colocaron seguidamente en torno del bien edificado altar y se lavaron las manos y cogieron los granos de cebada majada" (Il. I 447-449); "Tras hacer la súplica y espolvorear los granos de cebada majada" (Il. 448-440) ${ }^{42}$.

\section{DISCUSIÓN Y CONCLUSIONES}

Un primer aspecto que merece ser enfatizado en la obra homérica es su rol fundante en la Historia Natural desarrollada durante la antigüedad greco-latina. Se nombra por primera vez una proporción importante de la flora mediterránea, que describe más de cinco siglos después Teofrasto, discípulo de Aristóteles y considerado "el padre de la Botánica" -en su Historia de las plantas-. La denominación formal de las especies de plantas homéricas, con nombres latinos binomiales, la realiza $c a$. de 2500 años después Carlos Linneo, fundador de la Taxonomía biológica moderna, en Las especies de las plantas (Species plantarum 1753), permaneciendo vigentes hasta hoy la mayoría de estos nombres específicos. Asimismo, numerosos géneros, familias e incluso divisiones botánicas creadas por Linneo, se instituyen sobre la base de los nombres latinizados de

\footnotetext{
${ }^{40}$ Plinio el Viejo, en Naturalis Historia XII, 6 (3-5), relata la ruta recorrida por el plátano, desde que fuera por primera vez introducido en Italia, a causa de su sombra y añade que: "los plátanos ganaron celebridad por vez primera en el paseo de la Academia de Atenas, por uno cuya raíz - de treinta y tres codos- era más grande que sus ramas" (texto latino de Ernout 1952, traducción española de Manzanero Cano 2010). También el diálogo Fedro de Platón (Lledó 1988) transcurre a la sombra de un frondoso plátano (230 b-c).

${ }^{41}$ La palabra "cereal" deriva de "Ceres", diosa romana identificada con la griega Deméter.

${ }^{42}$ Los cereales tienen un gran valor simbólico en la mitología griega. De acuerdo con Segura \& Torres 2009 (p. 379), la diosa Deméter es "la encarnación mítica de la tierra nutricia, que hace germinar y desarrollarse las semillas que producen los frutos necesarios para la supervivencia del género humano, especialmente los cereales". Los autores agregan que Deméter "enseñó a Triptólemo el arte de sembrar y recoger el trigo y se dice que inventó el arado" (Ibid: 379).
}

plantas homéricas ${ }^{43}$. Además, la terminología morfológica básica de la botánica mantiene efectiva las raíces de las palabras inauguradas por Homero ${ }^{44}$.

La flora mediterránea adquiere en los poemas homéricos una significativa función/dimensión estética. Buena parte de los árboles y plantas emergen aquí y allá en la figura poética más recurrente de la poesía oral: el símil, que como se ha mostrado- es harto más frecuente en la Ilíada que en la Odisea. A diferencia de la Odisea, cuya trama se desarrolla en una gran variedad de escenarios geográficos, la acción de la Ilíada transcurre casi exclusivamente en la llanura de Troya, desprovista de bosques y verdes praderas. De allí que Homero, haciendo gala de un exquisito sentido del equilibrio, introduzca los árboles y plantas ausentes en el paisaje troyano, utilizando la figura del símil. El terrible, áspero y seco escenario de las batallas y de la muerte, que se suceden unas a otras en la gran mayoría de los cantos, se sublima por el recurso de la comparación de héroes y hazañas con elementos del mundo vegetal y la vida ${ }^{45}$.

No es trivial el hecho de que en la Ilíada los símiles con referencias botánicas aparezcan sobre todo al momento de señalar la muerte de un héroe, que fuerte y vigoroso, cae como una encina, un álamo o un pino. Pues Homero, el padre de la tragedia ${ }^{46}$, supo ver belleza allí donde otros verían solo muerte y desolación. Ese es uno de los grandes méritos de la poesía griega.

Así como gran parte de los magníficos símiles de la Ilíada logran expresar el radical vínculo entre el crecimiento y desmoronamiento de la naturaleza vegetal y el destino de la vida humana, el poema completo de la Odisea pareciera ser una gran metáfora de la búsqueda del sentido profundo que constituye la humanidad. Como se dijo antes, el delimitado espacio terrestre de la Ilíada contrasta con la inmensidad oceánica donde transcurre mayormente la Odisea, de cuyos contornos indefinibles van emergiendo, una a una, misteriosas islas ocupadas por vegetación selvática y

\footnotetext{
${ }^{43}$ Géneros Selinum, Asphodelos, Crocus, Donax, Cedrus, Cupressus, Fagus, Zea, Agrostis, Hyacinthus, Lotus, Schoenus, Phoenix, Platanus, Linum, Rosa; Familias Cupresáceas, Fagáceas, Platanáceas, Lináceas, Acantháceas, Ampelidáceas.

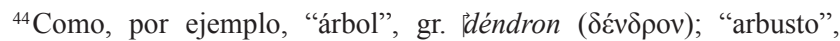

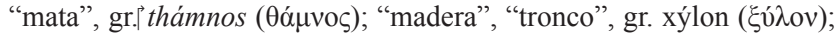

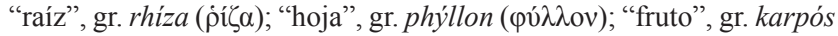

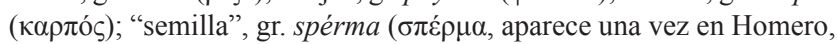
con sentido figurado, Od. V 490); "flor", gr. anthos (öv $\theta 0 \varsigma)$ ); "tirso", gr.

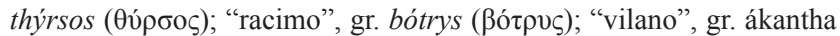

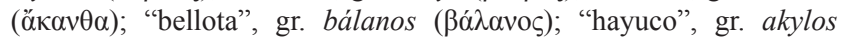

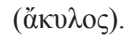

${ }^{45}$ Salvo la comparación que hace Tetis, entre la crianza de Aquiles y el cuidado de un viñedo (canto XVIII), todos los símiles en los que se realizan comparaciones con árboles y plantas se encuentran en los cantos donde se desarrollan combates (IV, V, VIII, XI, XII, XIII, XIV, XV, XVI, XVII), abarcándolos casi en su totalidad.

${ }^{46} \mathrm{El}$ primero de los trágicos, según Platón, República 607a (Eggers Lan 1986).
} 
delicados jardines, cuya flora constituye gran parte de las descripciones de este estudio.

Hay algo que tienen en común estos solitarios islotes que vertebran el espacio mítico del poema: todos ellos están habitados por seres fabulosos con modos de existencia no humanos, donde la exuberante naturaleza silvestre deviene espontáneamente y prodiga todos los bienes necesarios para una vida feliz. El fantástico jardín de los feacios es una muestra paradigmática de estos ambientes inmemoriales, donde los hombres comparten con los dioses, donde no hay trabajo ni fatiga, donde el tiempo y el espacio parecieran no existir -un espacio quimérico que rememora el mito de la edad de oro del mundo, que describiera por primera vez Hesíodo $^{47}$.

De diversas maneras, los habitantes de cada una de estas islas conspiran para que los navegantes pierdan la conciencia de su condición humana: sea la sumersión en una eterna y feliz existencia tutelada por los dioses, como entre los feacios; sea el perder la memoria del retorno, como entre los pacíficos lotófagos comedores del fruto del olvido; sea la bestialización sin tiempo, como el conjuro de Circe que torna en puercos a los humanos; sea un mundo salvaje, como entre los gigantes lestrigones o los solitarios cíclopes, sin leyes ni sociedades, que se alimentan de carne humana; sea la inspiración y gloria imperecedera que promete el canto de las sirenas; sea el eterno deleite de una inmortalidad divina que ofrece Calipso; sea la disolución en las tinieblas del país de los cimerios, el confín del mundo donde no llega la luz y habitan las almas informes de los muertos, sin rostro ni palabra.

Uno a uno van sucumbiendo los compañeros de Odiseo hasta que la nave mágica de los feacios lo devuelve-solitario, desamparado y dormido- al puerto de Forcis, la entrada a su isla de Ítaca. La duración de las plantas constituye el signo inequívoco del retorno de Odiseo al orden humano, a la continuidad del "tiempo recobrado". Odiseo reconoce el olivo sagrado al fondo del puerto de Forcis, al lado de la cueva de las náyades, las ninfas del agua, donde antaño rindiera hecatombes a los dioses. Odiseo recuerda el olivo con el que construyera su tálamo nupcial, inamovible y arraigado a la tierra de Ítaca, y esta es la prueba que necesita Penélope para el reconocimiento de su marido. Odiseo rememora, una a una, las plantas del huerto de Laertes, desde cuando su padre se las regalara en la niñez, y esta remembranza permite al padre reconocer a su hijo ${ }^{48}$.

\footnotetext{
${ }^{47}$ Hesíodo (Trabajos y días, 109-120): “Al principio los Inmortales que habitan mansiones olímpicas crean una dorada estirpe de hombres mortales [...] Vivían como dioses, con el corazón libre de preocupaciones, sin fatiga ni miseria [...] Poseían toda clase de deleites, y el campo fértil producía espontáneamente abundantes y excelentes frutos. Ellos contentos y tranquilos alternaban sus faenas con numerosos deleites".

${ }^{48}$ No es casual que las plantas señeras del retorno sean las cultivadas en un huerto o de gran importancia ritual, como el olivo. Como se ha
}

Más allá de la belleza poética de los símiles de la Ilíada, de los exquisitos escenarios naturalistas de la geografía botánica, de los episodios fantásticos que jalonan el exilio y retorno de Odiseo, quizás el significado más profundo del mito homérico -como asimismo de muchísimos otros mitos similares- sea simbolizar la inspiración divina que mueve el corazón del hombre, el radical sentido del ciclo de la vida y de la muerte, la persistencia de la memoria que permite el arraigo a lo humano, la relación con otros hombres como una forma de reconocimiento mutuo que constituye la comunidad. Así lo sugiere la extraordinaria acogida y proyección del poeta en todos los ámbitos de la cultura greco-latina, como asimismo en varias de las obras maestras de la filosofía, literatura y cine contemporáneos.

\section{AGRADECIMIENTOS}

Las autoras desean agradecer expresamente a dos revisores anónimos por la detenida lectura del manuscrito, sus importantes sugerencias y valiosa crítica.

\section{REFERENCIAS}

FuENTE (EDICIONES GRIEGAS Y LATINAS CON LAS RESPECTIVAS TRADUCCIONES UTILIZADAS):

Ernout, A., André, J. 1952. Pline 1' Ancíen: Naturalis HistoriaHistoire Naturelle. Paris, Les Belles Lettres (trad. esp. F. Manzanero Cano, I. García Arribas, M. L. Arribas Hernáez, A. M. Moure Casas \& J. L. Sancho Bermejo. Madrid, 2010). XII: 169 pp; XVI: 275 pp; XXIV:236 pp.

Hirtzel, F.A. 1990. P.Virgilii Maronis Opera. Clarendon Press, Oxford. $468 \mathrm{pp}$.

Hort, A. 1916. Historia plantarum. Ed. A. Hort, Theophrastus. Enquiry into plants, 2 vols., 1: 447 pp., 2: 320 pp., Cambridge, Mass.: Harvard University Press (trad. esp. J.M. Díaz-Regañón, Madrid, 2008. 531 pp.).

Lobel, E., Page, D.L. 1955. Poetarum Lesbiorum fragmenta. Ed. E. Lobel \& D.L. Page. Clarendon Press, Oxford. 337 pp.

Monro, D.B., Allen, Th.W. 1920. Homeri Opera. 3er. ed. Monro, D.B. \& T.W. Allen. Oxford: Clarendon Press. vols. 1-2: Homeri Ilias, 356 pp.-370 pp. (trad. esp. E. Crespo, Madrid, 1996); vols. 3-4: Homeri Odyssea, 242 pp.-227 pp. (trad. esp. J.M. Pabón, Madrid, 1982).

SECUNDARIA:

Álvarez, C., Iglesias, R.M. 1999. Ovidio: Metamorfosis. Cátedra, Madrid. $832 \mathrm{pp}$.

Bowra, C.M. 1933 La literatura griega. Trad. de Alfonso Reyes. Fondo de Cultura Económica, México, 1983. 245 pp.

CAlonge, J. 1985. Platón: Apología de Sócrates. Intr. Trad. y notas

destacado en el texto, en la botánica homérica las plantas intervenidas culturalmente son siempre las más sobresalientes, como obliga una concepción mítica de la naturaleza, -donde todos los aspectos relevantes siempre estarán íntimamente vinculados a las necesidades humanas-. 
de J. Calonge. Madrid, Gredos. 592 pp.

Díaz-Regañón, J.M. 2008. Introducción. Pp. 9-55. En: Teofrasto, Historia de las plantas. Gredos, Madrid. 531 pp.

EgGers Lan, C. 1986. Platón: República. Intr. trad. y notas de C. Eggers Lan. En Diálogos IV. Gredos, Madrid. 502 pp.

Forster, E.S. 1936. Trees and Plants in Homer. The Classical Review 50(3): 97-104.

Grimal, P. 1951. Diccionario de mitología griega y romana. Paidós, Buenos Aires, 1997. 635635 pp.

Liddell, H.G., Scott, R., Jones, H.S. 1989. A Greek-English Lexicon. University Press, Oxford. 2042+155 pp.

Lledó, E. 1985. Platón: Ion. En Diálogos I. Gredos, Madrid. 592 pp.

Lledó, E. 1988. Platón: Fedro. En Diálogos III. Gredos, Madrid. $416 \mathrm{pp}$.

López Eire, A. 1997. Introducción. En Homero: Ilíada. Cátedra, Madrid. 1034 pp.

Martínez, M. 2008. Descripciones de jardines y paisajes en la literatura griega antigua. Estudios griegos e indoeuropeos 18: 279-318.

Merry, W.W., Riddell, J., Monro, D.B. 1886-1901. Homer's Odyssey. Clarendon Press, Oxford. 615 pp.
Nestle, W. 1930. Historia de la Literatura griega. 2ed. Trad. E. Echauri. Labor, Buenos Aires, 1944. 371 pp.

Nestle, W. 1962. Historia del espíritu griego. 4ed. Trad. M. Sacristán. Ariel, Barcelona, 1987. 379 pp.

Отто, W.F. 1933. Dioniso; Mito y culto. 2ed. Trad. C. García O. Siruela, Madrid, 2001. 185185 pp.

Pastor Seco, M.I., Cuesta Pastor, J.M. 2004. Estudio sobre dos plantas homéricas: Mandragora y Moly. Espacio, Tiempo y Forma, Serie II, H. Antigua, 1.15: 87-94.

Pérez Jiménez, A., Martínez Díez, A. 1978. Hesíodo: Fragmentos. Intr. Trad. y notas de A. Pérez Jiménez \& A. Martínez Díez. Gredos, Madrid. 439 pp.

Plaitakis, A., Duvoisin, R.C. 1983. Homer's moly identified as Galanthus nivalis L.: physiologic antidote to stramonium poisoning. Clinical Neuropharmacology 6 (1): 1-5.

Segura, S., Torres, J. 2009. Historia de las plantas en el mundo antiguo. Publicaciones de la Universidad de Deusto, Bilbao. 478 pp.

SesAr, A. 1997. Mythos und Logos als Deutung der Wirklichkeit im Ganzen. Von der Metaphysik zur Metaphorik. Zeitschrift für Ganzheitsforschung. Neue Folge. 41, III: 115-135. 


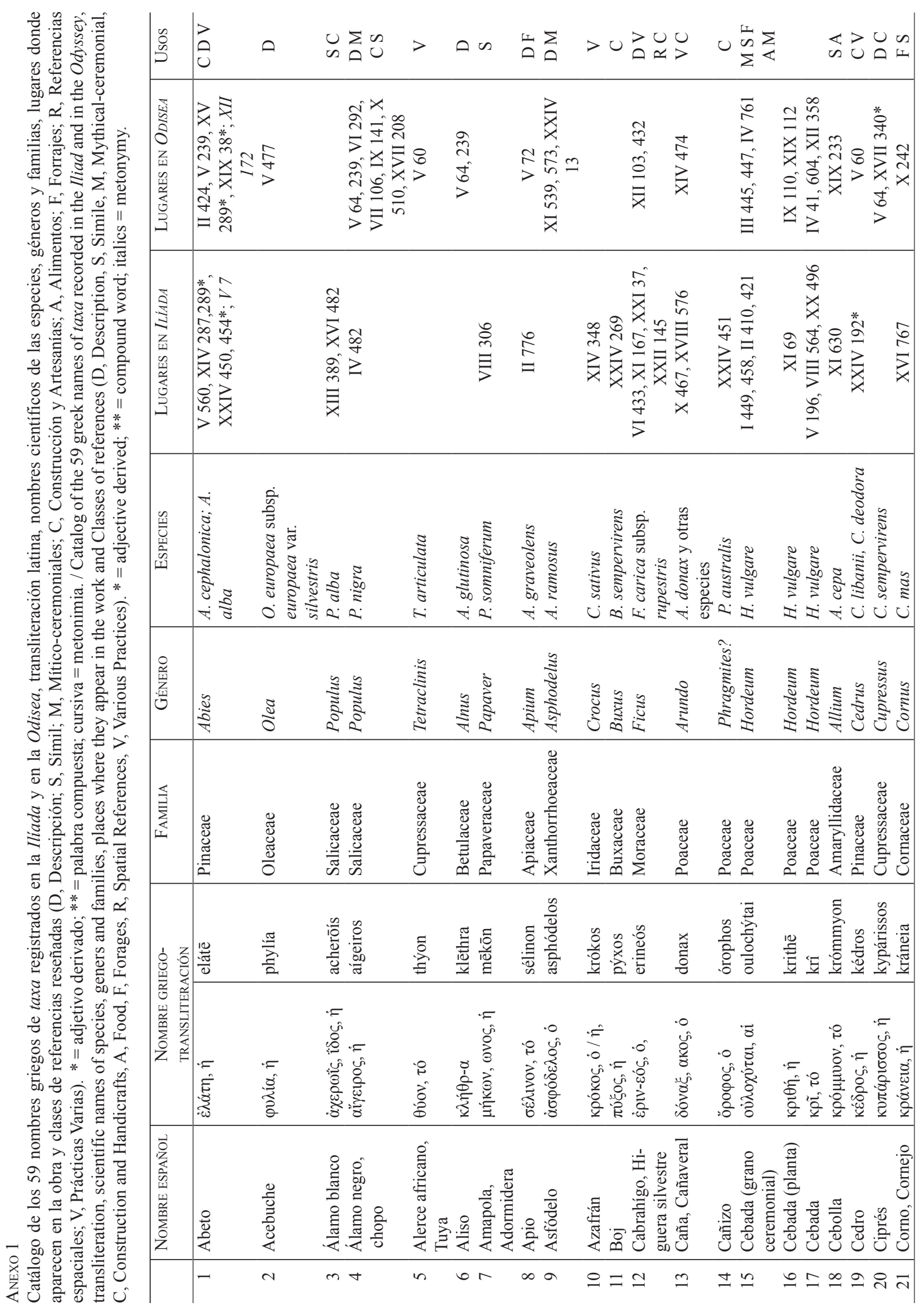




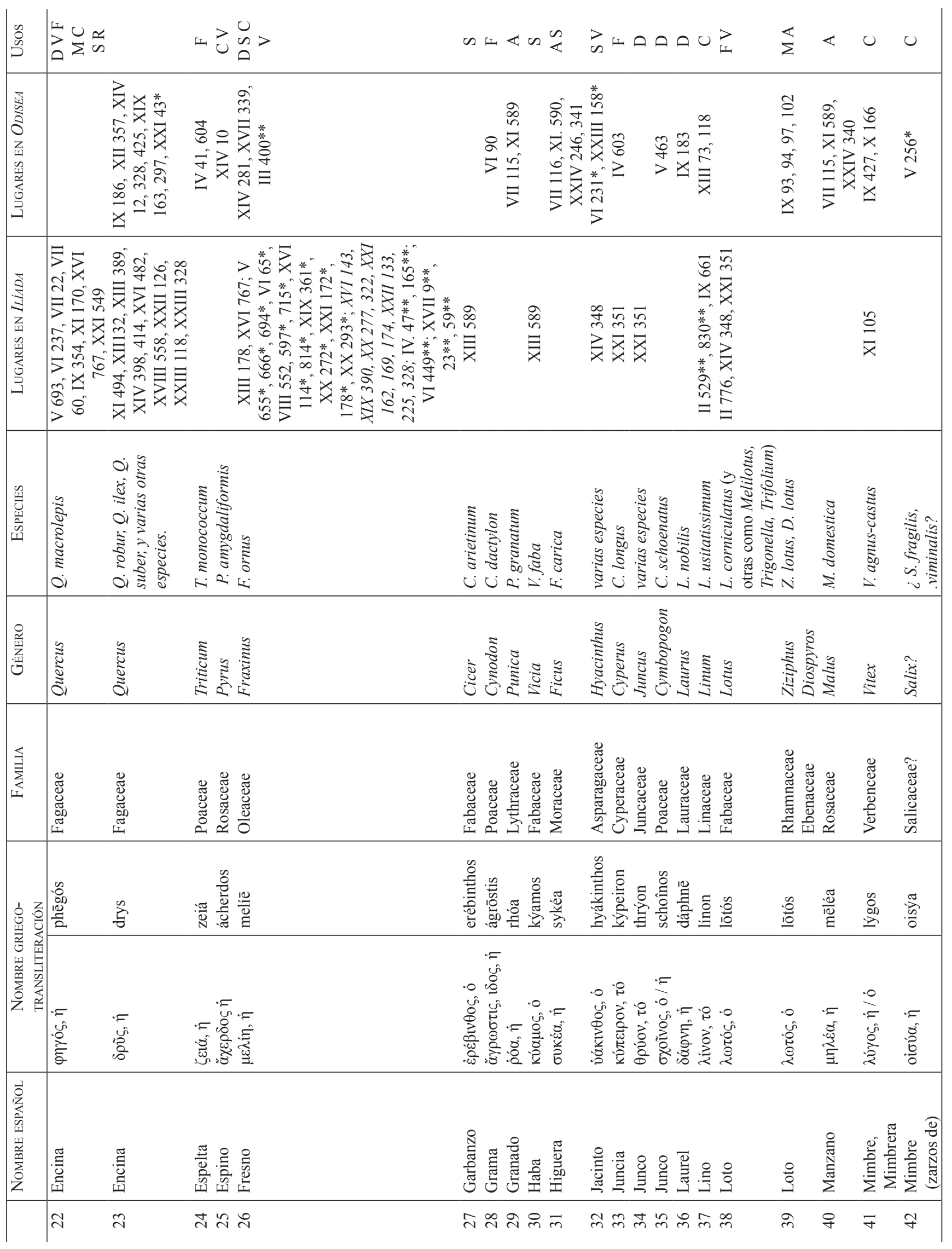




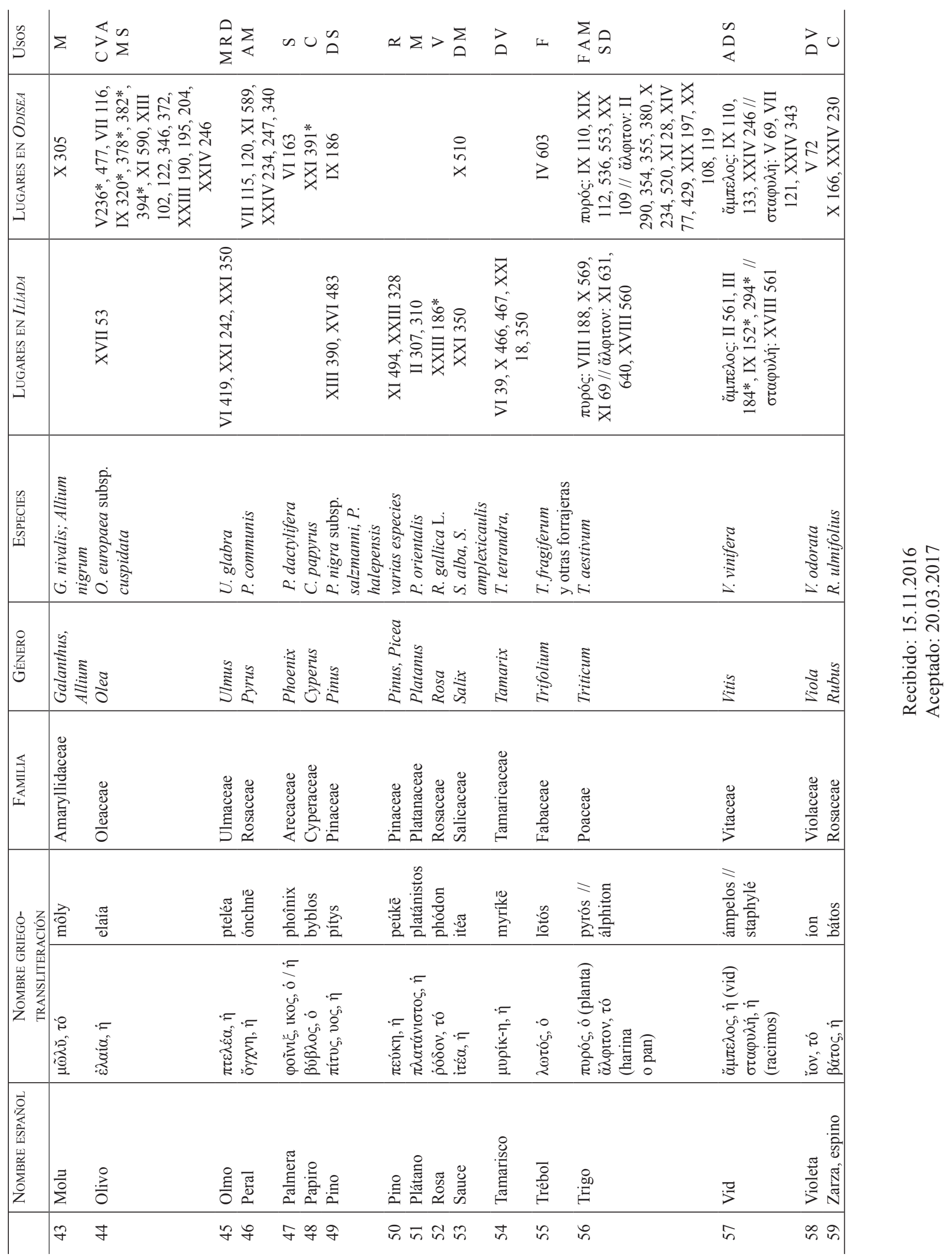

